\title{
Incremental sheet forming of thermoplastics: a review
}

\author{
Hui Zhu ${ }^{1} \cdot$ Hengan Ou ${ }^{1}$ (D) Atanas Popov ${ }^{1}$
}

Received: 3 May 2020 / Accepted: 7 September 2020 / Published online: 30 September 2020

(C) The Author(s) 2020

\begin{abstract}
Incremental sheet forming (ISF) is a promising flexible manufacturing process, which has been tested in sheet forming of various metallic materials. Although ISF-based forming of thermoplastics is relatively new, it has drawn considerable interests and significant progress has been made in recent years. This paper presents a review of concurrent research on the emerging trend of thermoplastic-focused ISF processes. Attention is given to the processing conditions including process setup, process parameters and forming forces. The deformation mechanism and failure behaviour during ISF of thermoplastics are evaluated, which leads to detailed discussions on the formability, effect of different process parameters and the forming quality such as geometric accuracy, surface finish and other consideration factors in ISF of thermoplastics. A comparison of important similarities and differences between ISF of thermoplastic and metallic materials is made. Finally, a brief discussion is provided on the technical challenges and research directions for ISF of thermoplastic materials in the future.
\end{abstract}

Keywords Incremental sheet forming · Thermoplastics · Process condition · Deformation and failure mechanism · Formability · Forming quality

\section{Introduction}

Incremental sheet forming (ISF) is a relatively new flexible forming process. As shown in Fig. 1, its principal concept is to progressively enable localised deformations by moving a generic shaped tool along a tool path to accumulate the whole shape of the part. In the early stage of ISF-related research, researchers are almost focused on single-point incremental forming (SPIF, one commonly used type of ISF), during which the flange of the sheet is clamped without further support and the sheet is maintained at a fixed position. In most cases of the early-stage SPIF, the sheet is deformed from the outside to the inside, and the centre of the sheet is moved downwards gradually. In the past decade, variants of ISF have been developed from SPIF including two-point incremental forming (TPIF) and double-side incremental forming (DSIF), as shown in Fig. 2. During the process of TPIF, the sheet is supported by a partial die or a full die at the other side

Hengan Ou

h.ou@ nottingham.ac.uk

1 Department of Mechanical, Materials and Manufacturing Engineering, Faculty of Engineering, University of Nottingham, Nottingham NG7 2RD, UK and is deformed from the inside to the outside with the flange moving downwards. During the process of DSIF, a second tool is used on the other side, serving as local support for the forming tool. The sheet is deformed under the cooperative effect of the forming tool and the supporting tool.

Comparing with traditional sheet forming processes, ISF is especially advantageous in manufacturing small-batch and customised non-axisymmetric sheet parts for potential applications in aerospace, automotive and other industries [1,2]. Therefore, ISF has been studied and tested to shape metal sheet parts since its inception. Most studies are focused on the deformation and fracture mechanism, formability improvement, different variants of ISF and their applicability to different metallic materials including aluminium alloy, magnesium alloy and pure titanium sheet. Up to now, numerous studies on ISF of sheet metals have been published, and a number of reviews have been reported by some researchers. Among them, Jeswiet et al. [3], for the first time, did a review on ISF and presented the genesis and the research progress before 2005. Ham et al. [4] discussed the influence of some ISF parameters using statistical plots. Echrif et al. [5] reviewed the state of the art at that time and briefly summarised the potential applications of ISF. The review done by Behera et al. [6] is focused on the development and research trends of ISF from 2005 to 2015. Duflou et al. [7] provided a 
Fig. 1 The basic principle of ISF and forming process (a) to (b)

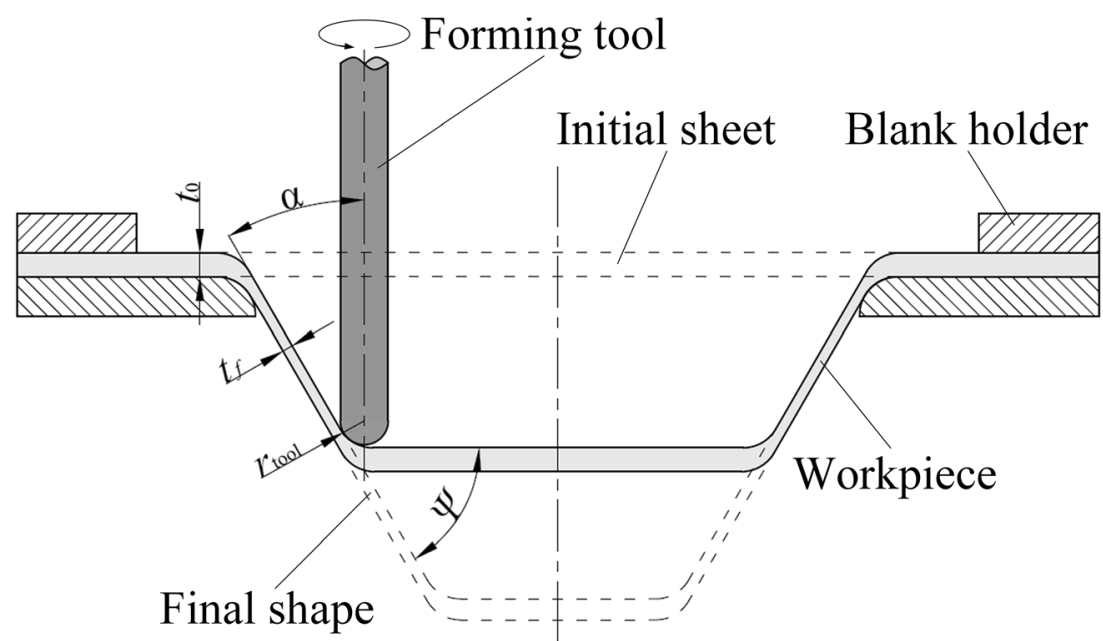

comprehensive review of the scientific progress and an outlook on future development. The review of $\mathrm{Li}$ et al. [8] is devoted to introducing the deformation mechanism, modelling methods, forming force prediction and other process problems. Ajay et al. [9], Tisza [10] and Sevsek and Pepelnjak [11] also presented a review on the scientific and technical issues of ISF. Apart from the above general reviews, Emmens et al. [12] and McAnulty et al. [13] provided reviews on the deformation mechanism and the improved formability of ISF. Another review by Emmens et al. [14] was focused on the history of ISF. Kumar et al. [15] gave a comparative analysis of the current achievement on the forming force in ISF. Ai and Long [16] summarised the material fracture mechanism and behaviour in ISF. Taleb-Araghi et al. [17], Liu et al. [18] and Peng et al. [19] reviewed the development of variants of ISF including hybrid ISF, heat-assisted ISF and DSIF.
Dewang et al. [20] focused on the formation of hole flanging using ISF, which is a quite promising research direction. Gatea et al. [21] focused on the influence of process parameters in ISF.

The above reviews are mainly related to the ISF for metallic systems. Franzen et al. [22], for the first time, attempted to form thermoplastics. Since then, ISF of thermoplastic materials has attracted increased attention for possible applications mainly because of its advantages including good resistance to impact and to temperature and bearing capacity $[23,24]$. In recent years, many researchers extended the scope to investigate the use of ISF to process different kinds of thermoplastics including polypropylene (PP), polyoxymethylene (POM), polyamide (PA), polycarbonate (PC), polyvinylchloride (PVC) and polyethylene terephthalate (PET) [25-28]. Yonan et al. [29] compared the main thermoplastic material
Fig. 2 Different variants of the ISF process. a TPIF with a partial die, $\mathbf{b}$ TPIF with a full die and $\mathbf{c}$ DSIF (a)

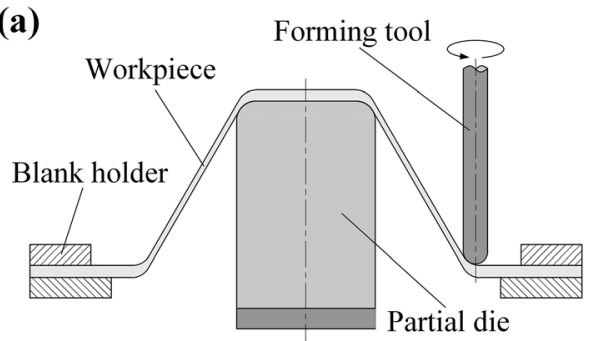

(c)

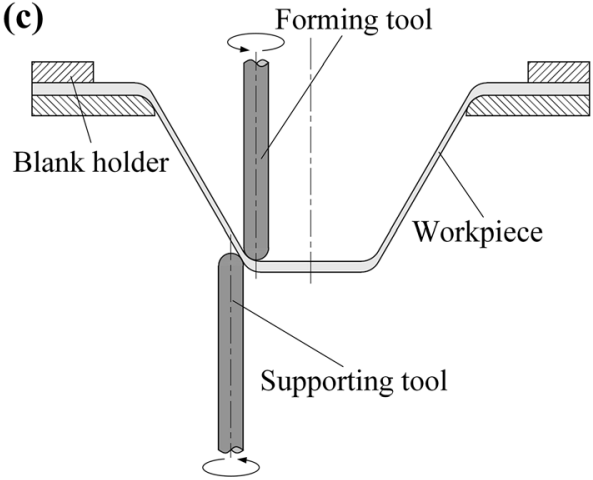

(b)

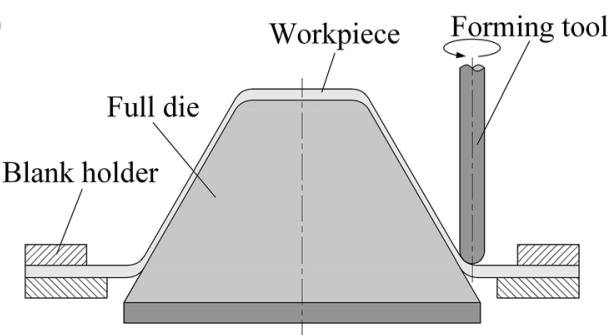


processing technologies from the technical and economic aspects. From their summarisation, the benefits of using ISF process to form thermoplastics appear to include low cost, low production rate, rapid prototype and small batch production, compared with traditional moulding and forming technologies.

Recently, most researchers investigated ISF of PVC thermoplastics with consideration of the basic process mechanism [22, 29-34]. In addition, considerable interest has been made to ISF of thermoplastic materials especially for such as customised cranial implant applications [35-39]. Centeno et al. [35] put forward a functional methodology to manufacture cranial implants by using ISF of thermoplastic sheet although there have been extensive reports on using ISF to design and manufacture cranioplasty implants of titanium sheets [40-43] as the ISF-based cranioplasty implant processing gives an excellent demonstration of the aforementioned advantages in manufacturing customised parts for medical applications.

As the early researches about ISF technology are mainly focused on metallic materials, there is an increased interest of transferring the research focus from metallic materials in ISF to thermoplastics, polymer foams [44], bilayer polymeric sheets $[45,46]$ and also polymer-based composite materials, which are considered a kind of hard-to-form material [47-53].

The aim of the paper is to review the current state of the art on ISF processing of thermoplastics, with specific attention given to process conditions (development of process setup, process parameters and forming forces), deformation mechanism and failure behaviour of thermoplastic materials in ISF, formability of thermoplastic materials in ISF (formability evaluation and effect of process parameters on formability), forming quality in ISF of thermoplastic materials (forming accuracy, surface finish of shaped parts and other consideration factors) and a comparison of the similarities and differences between ISF of thermoplastics and metals. A summary of the research challenges and future directions in this research area is presented as the conclusion.

To produce a replicable, exclusive and algorithmic literature review, the systematic review approach provided by Pickering and Byrne [54] and Pickering et al. [55] is used in this paper. This approach has also been used in the review of the formability in SPIF [13]. With ISF of thermoplastics as the topic, incremental sheet forming/ISF and thermoplastics are used as the search keywords to collect publications and only original research papers published from 2008 to 2020 are considered. The review results are presented in the following sections.

\section{ISF processing conditions}

ISF is performed by progressive localised deformations along a tool path to form the whole shape of the part. The process conditions are fundamental to ISF processing. Many researchers have investigated the process setup (Section 2.1) and process parameters (Section 2.2) of ISF of thermoplastic materials. During the ISF process, the forming force (Section 2.3) is also a significant factor because of its importance in selection of ISF forming tool.

\subsection{Process setup}

The setup of metallic ISF processing is generally comprised of four different parts: (1) positioning system, (2) forming tool, (3) clamping fixture, (4) support structure [7]. It is the same case for the ISF of thermoplastic materials. Franzen et al. [22], Silva et al. [56] and Yonan et al. [34] equipped a CNC machining centre with an experimental setup to perform ISF on PVC, PET and PC sheets, as shown in Fig. 3. The equipment consisted of the thermoplastic sheet blank, the blank holder, the backing plate and the rotating forming tool controlled by $\mathrm{CNC}$ machining programme. Medina-Sanchez et al. [31] developed an in-house fixing system to conduct SPIF on a milling machine to shape PVC sheet with a thickness of $3 \mathrm{~mm}$.

For polymeric materials, reduced strength and increased ductility can be obtained with the rise of forming temperature. During ISF, temperature elevation is useful to improve the formability of some hard-to-form polymeric materials. Therefore, ISF of thermoplastics is often assisted using a heating system in the setup [57]. Some researchers have developed different heating methods used in ISF process to elevate the forming temperature of thermoplastic sheets. When forming polymethyl methacrylate (PMMA) sheet and a composite material sheet made of polyamide-6 (PA 6) and short glass fibres, Conte et al. [48, 58] designed a heating system using an electric resistance of $2 \mathrm{~kW}$ as the heating source. In the system, a thermal isolated chamber was constructed inside of the metallic structure coated with refractory material. And then, the thermal power produced by electrical resistance heated up the air inside to enable heat transfer between the air and the thermoplastic materials. The temperature of the upper face of the sheet was monitored and controlled by a thermoscamera and a control unit. Ambrigio et al. [57] inherited the same heating system when they tried to form PMMA sheets using ISF. Okada et al. [50] realised local heating using a halogen lamp on the one side of the carbon fibre reinforced thermoplastic sheet and formed on the opposite side of the sheet using a hemispherical forming punch with a reciprocating motion. In the research of Sridhar and Rajenthirakumar [59], a heating coil is fixed and placed below the part to achieve the temperature elevation during SPIF process of PC sheet. It can be concluded that different heating methods have been attempted to conduct warm/hot incremental sheet forming of thermoplastic materials.

However, a heating system is not always essential in the ISF process of thermoplastics, especially when the given 

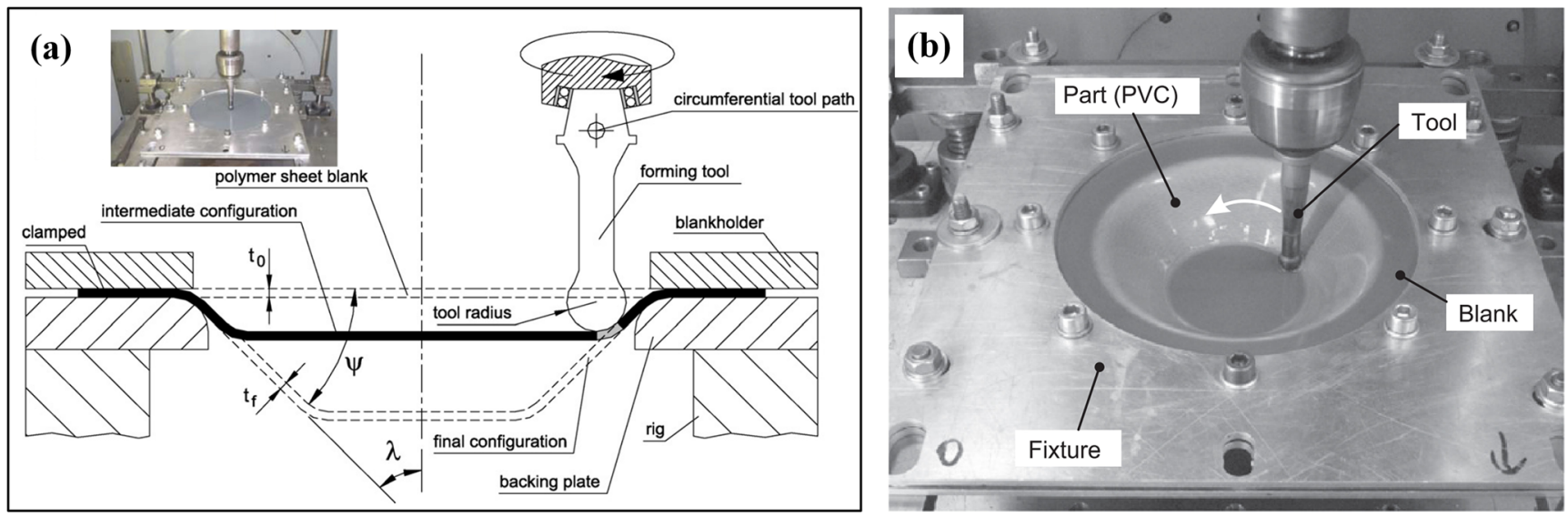

Fig. 3 a Schematic representation of a cross-section view [22] and b experimental setup of SPIF [34]

material has excellent formability, or the friction heat is sufficient to soften the material. Moreover, cold ISF could produce thermoplastic parts with higher strength and save energy and cost [34]. In the studies of Franzen et al. [22] and Silva et al. [33], PVC sheet parts were proved to be successfully formed with large drawing angle and forming depths at room temperature. Martins et al. [25], Marques et al. [60], Hussain et al. [61] and some other researchers found that cold ISF is a viable option for thermoplastics, which is an attractive and promising research aspect. On the other hand, in the study of Bagudanch et al. [30], the temperature rise resulting from the friction heat could reach about $50{ }^{\circ} \mathrm{C}$ above the room temperature at the tool tip using a spindle speed of $2000 \mathrm{rpm}$. This temperature rise was also presented by many other researchers, e.g. Medina-Sanchez et al. [31]. This leads to the relatively good material formability without pre-set temperature rise by external heating system.

\subsection{Process parameters}

The ISF process parameters include forming temperature, drawing angle $(\Psi)$, step size $(\Delta z)$, spindle speed $(\omega)$, feed rate, tool radius $\left(r_{\text {tool }}\right)$, initial sheet thickness $\left(t_{0}\right)$, tool shape and tool path. Among them, forming temperature, drawing angle, tool radius, step size, spindle speed and initial sheet thickness are important to the formability, failure and forming quality in ISF processing of thermoplastics. Therefore, these parameters are discussed below.

\subsubsection{Forming temperature}

Forming temperature can significantly influence material properties and thus exhibits non-negligible effects on the ISF process of thermoplastics. In general, the material formability can be improved at elevated temperature. The forming geometric accuracy and surface roughness would also be affected. The temperature elevation can be reached by not only external heating sources but also the heat of friction between sheet blanks and ISF tool during the forming process [62]. Both have been studied by researchers on their influence on the ISF forming quality.

Conte et al. [58] studied the effects of process temperature on the SPIF of PMMA sheet with a thickness of $2 \mathrm{~mm}$. According to their research results, the initial temperature arisen from external heating and the spindle speed was adjustable parameters to achieve an appropriate forming temperature without brittle fracture and excessive springback during the process. However, the surface quality of the part was damaged when a high spindle speed was applied. Therefore, adjusting the initial temperature before forming without increasing the spindle speed was an effective method to realise better forming quality of thermoplastic materials. In another research [48], the same authors investigated the effects of forming temperature on material formability, thickness distribution and the forming accuracy of a composite material sheet part made of PA 6 and short glass fibres. The authors found that better performance could be achieved at a higher temperature in ISF of thermoplastics. To maximise the effect of process temperature, Formisano et al. [63] observed that a reasonable localised temperature should be produced below the glass transition temperature, which was ideal to soften the thermoplastic sheet and keep the stiffness at a proper level. The similar conclusion was also reported by Kulkarni et al. [64].

\subsubsection{Drawing angle (wall angle)}

During the ISF process, a constant or varying drawing angle may be defined to form a specific geometry. The maximum drawing angle $\Psi_{\max }$ and the initial drawing angle $\Psi_{0}$ are considered two important parameters in ISF of thermoplastics. For metallic materials, the maximum drawing angle $\Psi_{\max }$ is used as a parameter to determine the formability [65]. However, for thermoplastic materials, in addition to the maximum drawing angle $\Psi_{\max }$ used as a significant parameter of material formability [21], researchers also consider initial drawing angle $\Psi_{0}$ as a parameter with an effect to the material 
formability. Therefore, as a parameter in ISF of thermoplastic materials, the initial drawing angle $\Psi_{0}$ has been studied widely and is believed to have a significant influence on the formability and forming quality of ISF.

As reported by Marques et al. [60], the initial drawing angle $\Psi_{0}$ has an influence on the formability of thermoplastic materials only varying from $30^{\circ}$ to $60^{\circ}$. It is noteworthy that with the increase of $\Psi_{0}$, the tendency of formability is different for different thermoplastics [26]. More detailed discussion is given in Section 4.2. Apart from material formability, the forming accuracy is also influenced by the initial drawing angle. The springback rises with the increase of the initial drawing angle, according to the study of Martins et al. [25].

\subsubsection{Tool radius}

Tool radius is an important parameter in the ISF process of thermoplastic materials in terms of both formability and forming quality. According to studies by Bagudanch et al. [62] and Hussain et al. [61], the increase of the tool radius leads to the elevation of local temperature due to increased friction heat resulting from the increased tool-sheet contact zone. Besides, the surface finish can be significantly influenced by the tool radius. Better surface quality can be produced by a tool with a smaller radius [22, 27]. Apart from causing the change of forming temperature and surface finish, the variation of tool radius can also have an influence on the material forming limit. In general, the material formability can be increased with the decrease of tool radius, according to the studies of Martins et al. [25] and Marques et al. [60]. The influence of tool radius on the formability of thermoplastic materials in ISF is discussed in detail in Section 4.2.

\subsubsection{Step size}

The step size is an important parameter related to the formability and forming quality for both metallic and thermoplastic materials. Edwards et al. [66] found that, in ISF of PC sheet, reduced springback can be realised via increasing the step size. Also, a smaller step size can lead to reduced thinning in ISF of composite materials, according to Conte et al. [48]. In another study, Bagudanch et al. [30] found out that the step size only has less influence on the maximum vertical force than on the surface roughness of the formed parts. From the micro aspect, the larger step size can cause greater void densities and thus the thermoplastic material formed using SPIF exhibits greater crystallinity than unformed material [67]. This may provide an explanation for the macro influence of step size on thermoplastic in ISF.

\subsubsection{Spindle speed}

Spindle speed plays an important role in the formability and surface finish and needs to be taken into consideration in the ISF process of thermoplastic materials. Medina-Sanchez et al. [31] and Bagudanch et al. [62] found that the increased spindle speed can lead to the temperature rise during the forming process resulting from more friction between sheet blanks and tools compared with a free rotating tool. Bagudanch et al. [30] also observed that the spindle rotation and higher spindle speed were found to not only decrease the maximum forming force but also help to improve the formability of PVC sheets, as also shown in the study of Le et al. [23]. However, it can have negative effects on the surface roughness of sheet parts, as also revealed by Conte et al. [58]. Therefore, to find an optimum spindle speed considering both the formability and surface roughness is of significance to the forming process. Besides, an increase in the spindle speed can lead to an earlier occurrence of wrinkle [67] and an increase in energy consumption [68].

\subsubsection{Initial sheet thickness}

Similar to the metallic system, the initial thickness of thermoplastic sheet was identified as one of the most important process parameters on the material formability in ISF of thermoplastics $[25,33,60]$. Apart from formability, the initial thickness can have an influence on the forming forces [30], the forming accuracy [34] and the surface roughness [68]. In some cases, the initial sheet thickness has a positive influence on the ISF process, such as improved material formability as investigated by many researchers $[25,33,60,68]$. However, in other cases, the increased initial thickness can cause an overestimated in-plane force and larger geometrical deviation, which may have a negative effect on the forming quality [34]. Therefore, care should be taken in the selection of a reasonable thickness to perform ISF of a thermoplastic sheet. The details of the influence of initial thickness on the material formability and the forming quality are presented in Sections 4 and 5.

\subsection{Forming force}

Forming force, especially the maximum forming force, is an important parameter in ISF processing and in selecting a suitable machine and forming tool. Forming force is a reaction to the material deformation in the process [69] and the adjustments of different parameters such as drawing angle, spindle speed, tool radius and step size. These parameters could have an influence on the formability, failure, forming accuracy and surface finish during the process. Bagudanch et al. [30] studied the effects of some main process parameters including step size, tool radius, feed rate and spindle speed, as well as sheet thickness on the maximum forming force in ISF process of 
PVC. The authors found the maximum forming force increased with the rise of tool radius, step size and initial thickness. It is worth noting that the increased spindle speed leads to a decrease in the maximum forming force due to the material softening resulting from temperature increase. Davarpanah et al. [67] presented the same finding that the forming force increased with the increase of step size and decrease of spindle speed when forming PVC and PLC sheets. Also, the authors hypothesised the increased in-plane forces could cause the sheet wrinkle because of the drag of sheet in pace with tool moving. Apart from the parameters mentioned above, the types and materials of forming tool and the tool path can also influence the forming forces. According to the study of Durante et al. [70], in ISF process of PC sheet with thickness of $1.9 \mathrm{~mm}$, the forming force produced by a rotating tool was a little higher than that produced by a fixed tool, and the toolpath strategy had an influence as well. In the study of Medina-Sanchez et al. [31], the aluminium tool produced a slightly higher forming force than the steel tool due to the lower temperature rise when using aluminium tool to form $3 \mathrm{~mm}$ PVC. In a recent study of Lozano-Sánchez et al. [71] and Sabater et al. [72], spindle speed and tool radius were found to be most influential on the maximum forming force for ultra-high molecular weight polyethylene (UHMWPE) and polycaprolactone (PCL) sheets. As demonstrated, the maximum forming force is decreased with the increased spindle speed and the decreased tool radius. To predict axial force in SPIF of thermoplastic sheets, two procedures were proposed by Medina-Sanchez et al. [73], the first of which is based on the finite element simulation, the other is a simple semi-analytical model. The results showed reasonable agreement with the experimental measurements with a relative error of less than $10 \%$.

\section{Deformation and failure mechanism}

It was found that ISF can effectively increase the formability of not only metals but also thermoplastics. The reasons for the improved formability of metallic materials in ISF have been studied and reviewed widely, but for thermoplastics, there is still a lack of review to bring previous research findings together. This section firstly introduces the deformation mechanism of polymeric materials to analyse the fundamentals for the enhanced formability. Then the discussion is focused on failure, which is the limitation for the material formability in ISF processing of thermoplastic materials.

\subsection{Deformation mechanism}

For metallic materials, ISF can improve material formability in ISF compared with other traditional sheet plastic forming process such as bulging and deep drawing $[11,13]$ because of the highly localised plastic deformation. This is the same for thermoplastic materials. As the use of ISF to form thermoplastic materials claims further improved formability, better forming accuracy and acceptable surface finish, the understanding of the material deformation mechanism is of great significance for further investigation. The deformation mechanism of thermoplastics in ISF is being studied by many researchers.

\subsubsection{Deformation mechanics}

It has been widely acknowledged that stretching leading to membrane strain is the dominant deformation mode in the ISF process. In SPIF of not only metallic but also thermoplastic materials, there are three basic deformation modes including (a) plane strain stretching on flat surfaces, (b) plane strain stretching on rotational symmetric surfaces and (c) equibiaxial stretching at corners by Marques et al. [60] as illustrated in Fig. 4.

For the deformation mode of plane strain stretching conditions, Silva et al. [74] proposed a theoretical framework of membrane analysis on the deformation mechanism of sheet metal in rotational symmetric SPIF. In subsequent research, the authors innovatively extended the membrane approach developed before to model the cold plastic deformation of thermoplastic materials with the typical pressure-sensitive yield surfaces [33]. In their derivation, some assumptions were set up to simplify the model: (1) bending moments were neglected and circumferential, meridional and thickness stresses are principal stresses; (2) the material is rigidperfectly plastic and strain hardening effects are ignored; (3)

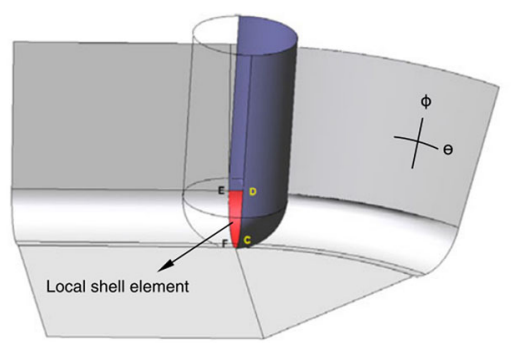

(a)

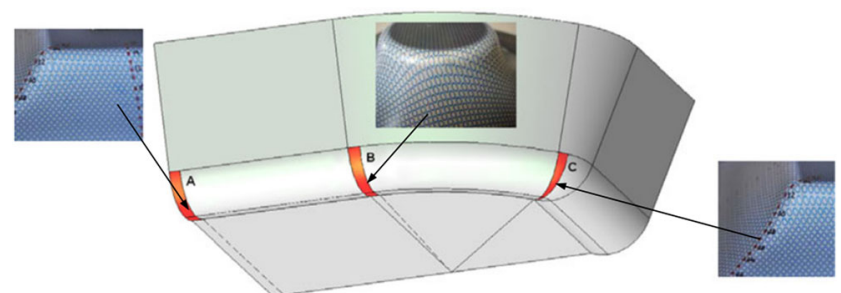

(b)

Fig. 4 Essentials for the theoretical framework based on membrane analysis [60]. a Schematic representation of the local contact area (shell element) between the tool and sheet placed immediately ahead. b Instantaneous deformation zones and evidence of the extreme modes of deformation obtained from circle grid analysis 
the utilised yield criteria was the pressure-modified Tresca and von-Mises criteria; (4) no material anisotropic effects are taken into account; (5) rate effects are neglected; (6) the frictional stress at the contact surface between tool and sheet is just made of in-plane meridional and circumferential components. The local shell element utilised in their research to analyse the membrane equilibrium conditions and the stresses acting on the element are illustrated in Fig. 5. Three analytical equations are used to express force equilibrium along circumferential, meridional and thickness directions and can be deduced and simplified as follows:

$\mathrm{d} \sigma_{\theta}=-\mu_{\theta} \sigma_{\mathrm{t}} \frac{r \mathrm{~d} \theta}{t} \cong-\mu_{\theta} \sigma_{\mathrm{t}}$

$\frac{\sigma_{\mathrm{t}}}{t}+\frac{\sigma_{\phi}}{r_{1}}+\frac{\sigma_{\theta}}{r_{2}}=0$

$\frac{\mathrm{d} \sigma_{\phi}}{\mathrm{d} r}+\frac{\sigma_{\phi}-\sigma_{\theta}}{r}+\frac{\mu_{\phi} \sigma_{\mathrm{t}}}{t \sin \alpha}+\frac{\sigma_{\phi}}{t} \frac{\mathrm{d} t}{\mathrm{~d} r}=0$

where $\sigma_{\theta}, \sigma_{\mathrm{t}}$ and $\sigma_{\phi}$ are the circumferential, thickness and meridional stress, respectively; $\mu$ is the coefficient of friction; $t$ is the thickness of the sheet; $r_{1}$ is the radius of curvature of meridian at the element (radius of the tool, $r_{1}=r_{\text {tool }}$ ).

After deriving the stress state of the local shell element 'CDEF' by taking into account the rigid-plastic constitutive equations derived according to the modified version of Tresca and von-Mises criteria, the authors drew the conclusion that the principal stress distribution of the shell element is always identified as follows, regardless of what constitutive equations applied on the thermoplastic sheet:

$\sigma_{\phi}=\sigma_{1}>0$

$\sigma_{\theta}=\sigma_{2}$

$\sigma_{\mathrm{t}}=\sigma_{3}<0$

where $\left|\sigma_{t}\right|<\left|\sigma_{\phi}\right|$. In detail, the stress state can be described using the following expressions:

$\sigma_{\phi}=\frac{\left(\sigma_{\mathrm{Y}} \sqrt{1-\beta \sigma_{\mathrm{kk}}}\right)}{\left(1+\frac{t}{r_{\mathrm{tool}}}\right)}>0$
$\sigma_{\theta}=\frac{1}{2\left(\sigma_{\phi}+\sigma_{\mathrm{t}}-\beta \sigma_{\mathrm{Y}}\right)}$
$\sigma_{\mathrm{t}}=-\frac{\left(\sigma_{\mathrm{Y}} \sqrt{1-\beta \sigma_{\mathrm{kk}}}\right)}{\left(\frac{t}{r_{\mathrm{tool}}}+t\right)}<0$

where $\sigma_{\mathrm{Y}}$ is the geometric mean of the tensile and compressive yield strengths $\left(\sigma_{\mathrm{Y}}=\sqrt{\sigma_{\mathrm{YC}} \cdot \sigma_{\mathrm{YT}}}\right)$ and $\beta$ is the normalised
Fig. 5 Membrane analysis of SPIF [33]. a Schematic representation of the local contact area between the tool and sheet placed immediately ahead. b Approximation of the local contact area by a shell element. c Cross-section view showing the acting stresses in meridional, circumferential and thickness directions (a)

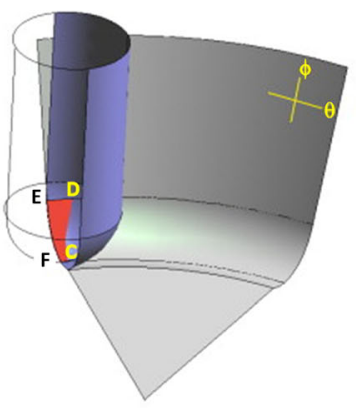

(b)

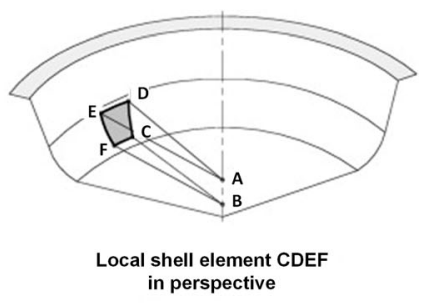

(c)

cross section view (cut by a meridional plane)
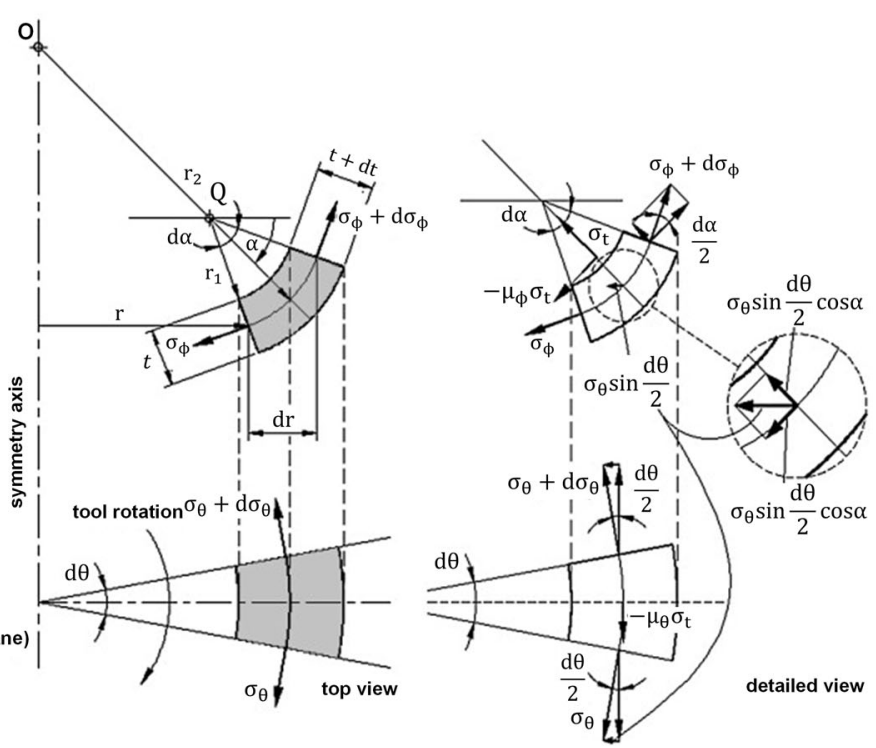
Table 1 State of stress and strain in the small localised plastic zone of the SPIF of thermoplastics and metals [60]

\begin{tabular}{|c|c|c|c|c|}
\hline & & State of strain & State of stress & Hydrostatic stress \\
\hline \multirow[t]{2}{*}{$\begin{array}{l}\text { SPIF of } \\
\text { thermoplastics }\end{array}$} & $\begin{array}{l}\text { Plane strain } \\
\text { conditions [33] }\end{array}$ & $\begin{array}{l}\mathrm{d} \varepsilon_{\phi}=-\mathrm{d} \varepsilon_{\mathrm{t}}>0 \\
\mathrm{~d} \varepsilon_{\theta}=0 \\
\mathrm{~d} \varepsilon_{\mathrm{t}}<0\end{array}$ & $\begin{array}{c}\sigma_{\phi}=\sigma_{1}=\left(\sigma_{\mathrm{Y}} \sqrt{1-\beta \sigma_{\mathrm{kk}}}\right) / \\
\left(1+t / r_{\text {tool }}\right)>0 \\
\sigma_{\theta}=\sigma_{2}=1 / 2\left(\sigma_{1}+\sigma_{3}-\beta \sigma_{\mathrm{Y}}\right) \\
\sigma_{\mathrm{t}}=\sigma_{3}=-\left(\sigma_{\mathrm{Y}} \sqrt{1-\beta \sigma_{\mathrm{kk}}}\right) / \\
\left(t / r_{\text {tool }}+t\right)<0\end{array}$ & $\begin{array}{c}\sigma_{\mathrm{m}}=\left(\sigma_{\mathrm{Y}} \sqrt{1-\beta \sigma_{\mathrm{kk}}} / 2\right)\left[\left(r_{\text {tool }}-t\right) /\left(r_{\text {tool }}+t\right)\right. \\
\quad]-(1 / 6) \beta \sigma_{\mathrm{Y}}\end{array}$ \\
\hline & $\begin{array}{r}\text { Equi-biaxial } \\
\text { stretching }\end{array}$ & $\begin{array}{l}\mathrm{d} \varepsilon_{\phi}=\mathrm{d} \varepsilon_{\theta}>0 \\
\mathrm{~d} \varepsilon_{\mathrm{t}}<0\end{array}$ & $\begin{array}{l}\sigma_{\phi}=\sigma_{\theta}=\sigma_{1}=\left(\sigma_{\mathrm{Y}} \sqrt{1-\beta \sigma_{\mathrm{kk}}}\right) / \\
\left(1+2 t / r_{\text {tool }}\right)>0 \\
\sigma_{\mathrm{t}}=\sigma_{3}=-2\left(\sigma_{\mathrm{Y}} \sqrt{1-\beta \sigma_{\mathrm{kk}}}\right) / \\
\left(t / r_{\text {tool }}+2 t\right)<0\end{array}$ & $\begin{array}{l}\sigma_{\mathrm{m}}=\left(2 \sigma_{\mathrm{Y}} \sqrt{1-\beta \sigma_{\mathrm{kk}}} / 3\right)\left[\left(r_{\mathrm{tool}}-t\right) /\right. \\
\left.\quad\left(r_{\text {tool }}+2 t\right)\right]\end{array}$ \\
\hline \multirow[t]{2}{*}{$\begin{array}{l}\text { SPIF of metals } \\
\quad[75]\end{array}$} & $\begin{array}{l}\text { Plane strain } \\
\text { conditions }\end{array}$ & $\begin{array}{l}\mathrm{d} \varepsilon_{\phi}=-\mathrm{d} \varepsilon_{\mathrm{t}}>0 \\
\mathrm{~d} \varepsilon_{\theta}=0 \\
\mathrm{~d} \varepsilon_{\mathrm{t}}<0\end{array}$ & $\begin{array}{l}\sigma_{\phi}=\sigma_{1}=\sigma_{\mathrm{Y}} /\left(1+t / r_{\text {tool }}\right)>0 \\
\sigma_{\theta}=\sigma_{2}=1 / 2\left(\sigma_{1}+\sigma_{3}\right) \\
\sigma_{\mathrm{t}}=\sigma_{3}=-\sigma_{\mathrm{Y}}\left(t / r_{\text {tool }}+t\right)<0\end{array}$ & $\sigma_{\mathrm{m}}=\left(\sigma_{\mathrm{Y}} / 2\right)\left[\left(r_{\text {tool }}-t\right) /\left(r_{\text {tool }}+t\right)\right]$ \\
\hline & $\begin{array}{r}\text { Equi-biaxial } \\
\text { stretching }\end{array}$ & $\begin{array}{l}\mathrm{d} \varepsilon_{\phi}=\mathrm{d} \varepsilon_{\theta}>0 \\
\mathrm{~d} \varepsilon_{\mathrm{t}}<0\end{array}$ & $\begin{array}{l}\sigma_{\phi}=\sigma_{\theta}=\sigma_{1}=\sigma_{\mathrm{Y}} /\left(1+2 t / r_{\text {tool }}\right)>0 \\
\sigma_{\mathrm{t}}=\sigma_{3}=-2 \sigma_{\mathrm{Y}}\left(t / r_{\text {tool }}+2 t\right)<0\end{array}$ & $\sigma_{\mathrm{m}}=\left(2 \sigma_{\mathrm{Y}} / 3\right)\left[\left(r_{\text {tool }}-t\right) /\left(r_{\text {tool }}+2 t\right)\right]$ \\
\hline
\end{tabular}

form of the strength-differential effect of the cold deformation of thermoplastic materials $\left(\beta=\left(\sigma_{\mathrm{YC}}-\sigma_{\mathrm{YT}}\right) / \sigma_{\mathrm{Y}}^{2}\right)$.

In terms of the deformation mode of equi-biaxial stretching conditions, Marques et al. [60] extended the analytical framework for the condition of rotational symmetry to the corner of the formed part to make both these two extreme and special deformation modes focused on SPIF of thermoplastic materials. The authors followed the analytical procedures used by Silva et al. [33] and obtained the stress distribution under the condition of equi-biaxial stretching. Based on previous study results and their derivation, the authors summarised the stress and strain state in the small localised plastic zone of SPIF of thermoplastic and metallic materials under both plane strain conditions and equibiaxial stretching conditions, as shown in Table 1.

In Table $1, \beta$ is the normalised form of the strengthdifferential effect due to the difference between yield strengths in tension $\sigma_{\mathrm{YT}}$ and compression $\sigma_{\mathrm{YC}}\left(\beta=\sigma_{\mathrm{Y}}\left(\sigma_{\mathrm{YC}}-\sigma_{\mathrm{YT}}\right) / 2\right)$. In the metallic system, the strength-differential effect is null, but for thermoplastic materials, the strength-differential effect exists. This leads to the above difference between the SPIF of thermoplastics and metals in Table 1.

Apart from the above membrane analysis, Bagudanch et al. $[76,77]$ attempted to find a suitable material constitutive model to describe the stress-versus-strain states of PVC and PC sheet and further to be used in FE simulation of ISF. Sy et al. [78] selected a modified viscoelasticity theory based on overstress and the simulation and experimental results showed good agreement for the prediction of the thickness and the forming accuracy. Furthermore, Yonan et al. [34, 79] developed a non-linear visco-plastic material model used in ISF of thermoplastics and extended it to the FE simulation of PVC parts shaped by SPIF. However, this material model has limited applicability only with small deformations, making it difficult to analyse the plastic flow and the stress states for large strain. To solve this problem, the authors subsequently proposed an alternative and effective method, focusing on the characterisation of plastic flow and failure in SPIF of thermoplastic materials [29]. In their methodology, the constitutive equations relating the in-plane strain increments $\left(\mathrm{d} \varepsilon_{1}\right.$ and $\left.\mathrm{d} \varepsilon_{2}\right)$ with the applied stresses $\left(\sigma_{1}\right.$ and $\left.\sigma_{2}\right)$ are expressed by the following equations:

$$
\begin{aligned}
& \mathrm{d} \varepsilon_{1}=\frac{\mathrm{d} \bar{\varepsilon}}{\bar{\sigma}}\left(\sigma_{1}-\frac{1}{2} \sigma_{2}\right) \\
& \mathrm{d} \varepsilon_{2}=\frac{\mathrm{d} \bar{\varepsilon}}{\bar{\sigma}}\left(\sigma_{2}-\frac{1}{2} \sigma_{1}\right)
\end{aligned}
$$

where $\bar{\sigma}$ and $\bar{\varepsilon}$ are the effective stress and strain, respectively. In the above equations, the principal in-plane stresses can be calculated using the following equations:

$$
\begin{gathered}
\sigma_{1}=\frac{\bar{\sigma}}{\sqrt{\left(1-\alpha+\alpha^{2}\right)}} \\
\sigma_{2}=\frac{\alpha \bar{\sigma}}{\sqrt{\left(1-\alpha+\alpha^{2}\right)}}
\end{gathered}
$$

where $\alpha=\sigma_{2} / \sigma_{1}=(2 \beta+1) /(2+\beta)$ and $\beta=\mathrm{d} \varepsilon_{2} / \mathrm{d} \varepsilon_{1}=\varepsilon_{2} / \varepsilon_{1}$.

The above deformation mechanics plays an important role in revealing the strain and stress distribution in the small contact area between the forming tool and the thermoplastic sheet, where plastic deformation occurs. Consequently, it helps understand the mechanism behind the fracture of thermoplastic materials in ISF and the improved formability and can help to explain the relevant experimental observation.

\subsubsection{Microstructure evolution under deformation}

The microstructure evolution of thermoplastics during the ISF process is relatively complicated and of significance to the 
deformation behaviour. In general, the microstructure has an interaction effect with the deformation in the forming process.

Under the deformation of ISF, voids or pores may occur in the thermoplastic materials during the process $[67,80]$, as shown in Fig. 6. Davarpanah et al. [67] found the increase of void density in the formed PLA material can lead to the enhanced formability. In other studies [81, 82], the authors observed there is a change in orientation of crystalline lamella and molecular chain orientation in thermoplastics due to the deformation of ISF process with a slight change in the total degree of crystallinity. The schematic for the orientation change in ISF could be presented as Fig. 7. The authors thought this change may have an influence on sheet failure and forming forces. Further, Lozano-Sanchez et al. [71] found that polymer chains prefer to be oriented in different directions on the inner and outer surfaces of the shaped parts with a geometry of pyramid. On the inner surface, the horizontal orientation of chains is caused by the tool path, while on the other surface, the polymer chains are mainly pulled downwards, and the orientation of chains is vertical. Also, it was found that there may be an alpha star transition $\left(T_{\alpha}{ }^{*}\right)$ occurring in PCL and UHMWPE materials during ISF process, which is associated with the slippage between crystallites, when the process temperature is able to drive the transition.

\subsection{Failure behaviour}

It is well acknowledged that the failure behaviour of thermoplastic materials in ISF depends on the stress and strain state of material under the effect of forming tool [83]. As demonstrated in Section 3.1, the deformation mechanics, which plays a significant role in the failure mechanism of thermoplastics in ISF, has been summarised. Therefore, this section is mainly focused on how to characterise the failures of thermoplastic materials in ISF based on the above-summarised deformation mechanics.
In ISF of thermoplastics, there are three failure modes proposed by Franzen et al. [22], i.e., in-plane fracture, wrinkle and oblique fracture, which limit the material formability during the forming process. The three modes are described as follows.

Mode 1: In-plane fracture by ductile tearing along the circumferential direction, at the transition area between the inclined wall and the corner of formed parts, as seen in Fig. 8a and c. This failure mode is caused by stretching mechanisms owing to meridional tensile stress $\sigma_{\phi}$.

Mode 2: Wrinkle of the sheet along the inclined wall of the part from the immediate proximity of the corner, as illustrated in Fig. $8 \mathrm{a}$ and c. This failure mode is related to the twist [84] of radial cross-sectional planes caused by the movement of the forming tool along the spiral path, and is expected to occur at thinner sheet parts.

Mode 3: Oblique fracture of the sheet in the bisector direction of the $\theta-\phi$ surface on the wall of the shaped part, as shown in Fig. $8 \mathrm{~b}$ and d. This failure mode always arises from the redundant straining because of simultaneous straining by shearing on the $\theta-\phi$ surface and by bending, followed by additional unbending, along the $\theta$ direction.

Among the above-described failure modes, Failure Mode 1, i.e. in-plane fracture, is generally observed in ISF of metal sheet parts as well, while Failure Modes 2 and 3, i.e. wrinkle and oblique fracture, are unique failure behaviours in ISF of thermoplastic sheet parts.

Apart from the above failure modes, a significant phenomenon observed in ISF of thermoplastic materials is there is no obvious necking before fracture. For metallic system, fracture with gradual necking or without necking depends on the material [85-87] although in most cases there is no necking observed. Marques et al. described the phenomenon of the fracture without necking before as necking seems to be postponed or even suppressed [60]. Many researchers also verified the phenomenon in thermoplastic system either using the method of comparing the experimental strain of formed parts with the FFLs $[25,33]$ or through observing the fracture surface after
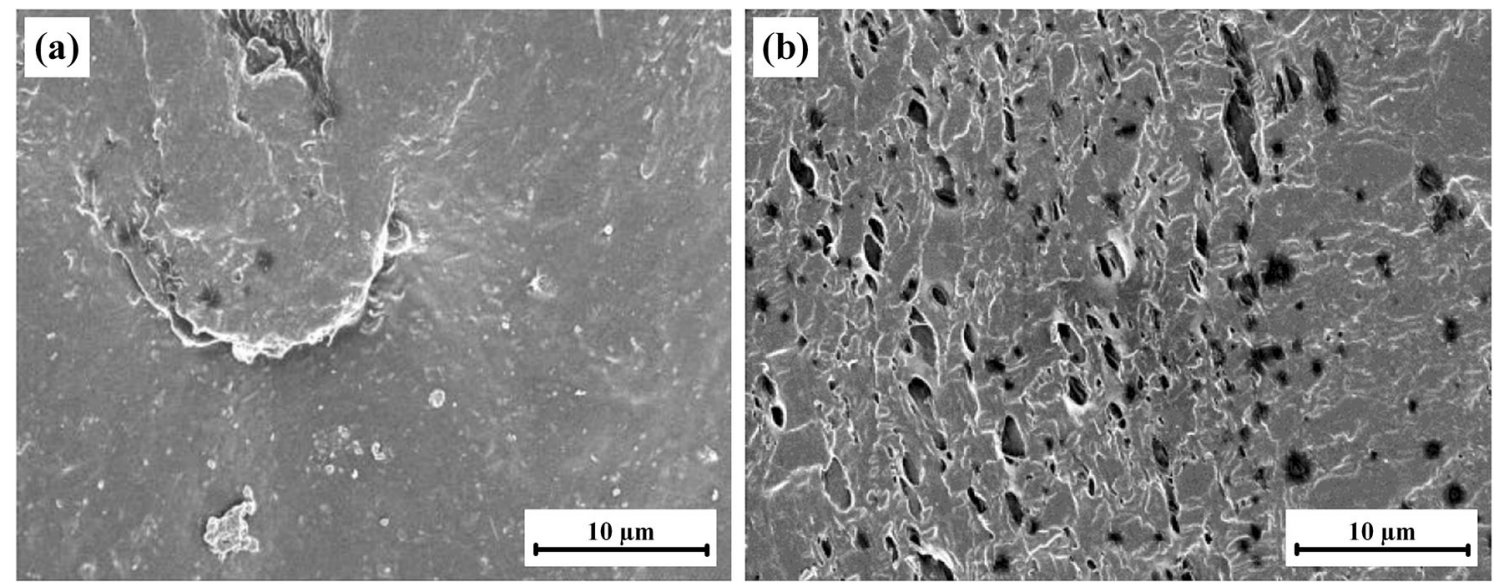

Fig. 6 SEM micrographs of PLA funnel part [67]: a original material and $\mathbf{b}$ formed part 
Fig. 7 Schematic representation of the orientation of polymer chains reorientation during SPIF
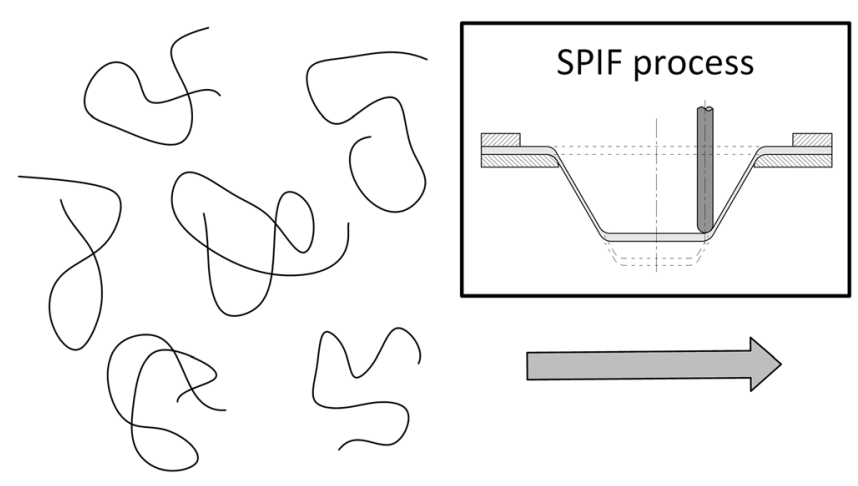

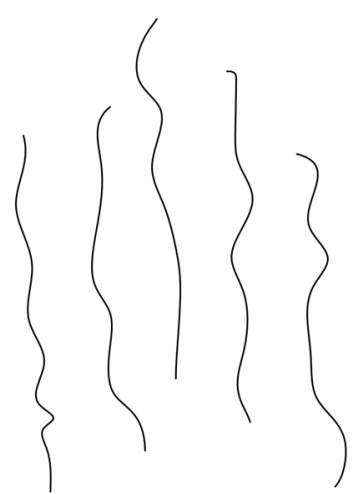

crack [88]. Bagudanch et al. [88] investigated the fracture morphologies of thermoplastic materials in ISF along different strain paths. As shown in Fig. 9, the suppression of necking before fracture can be observed both on the flat surface under plane strain state and at the corner under biaxial strain state, which are two extreme strain distributions in ISF.

\section{Formability of thermoplastic materials}

It was reported that in ISF with a certain range of parameters, materials are deformed locally with a stable straining and uniform thinning, which directly contributes to the suppression of necking and thus enhances the material formability in ISF [12, 33], while some other authors stated the improved formability results from the through-thickness shear [89]. This section aims to discuss the strategies to evaluate material formability in ISF of thermoplastics and the effects of different parameters mentioned in Section 2.2 on the formability.

\subsection{Formability evaluation}

Material formability in ISF is often characterised using forming limit diagrams (FLDs), following the same method as the traditional sheet forming technologies. The limit strains at the area where failures occur are important components of an FLD. As a result, there are two curves in FLDs to describe the formability in the sheet forming process determined by different beginning modes of fracture: (1) local necking, i.e. forming limit curve (FLC); (2) direct ductile fracture, i.e., fracture forming line (FFL). In ISF of thermoplastic materials, there is no obvious necking occurring before fracture. Taking
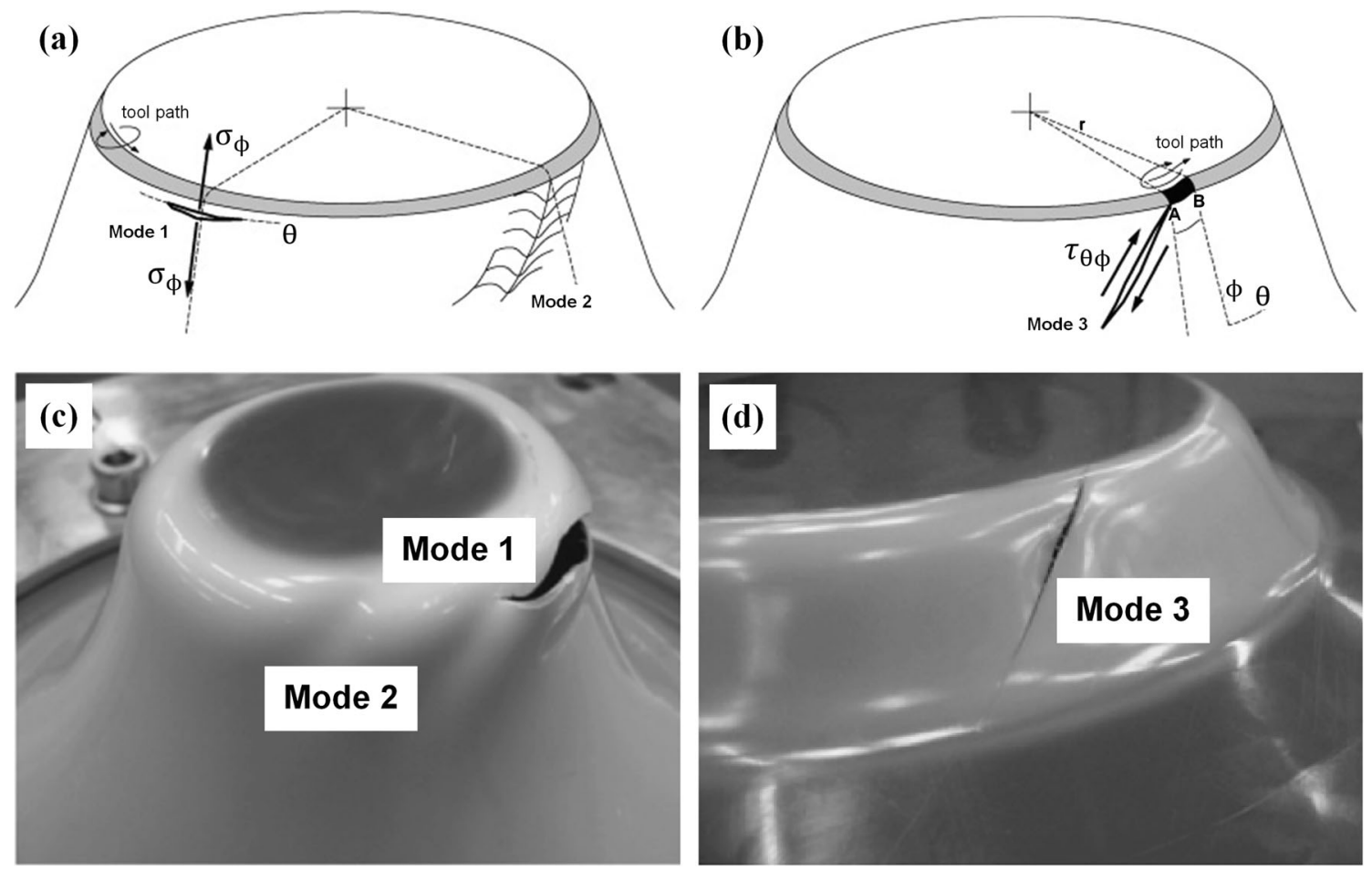

Fig. 8 Schematic illustration (a, b) and experimental observation (c, d) [22] of Failure Modes 1, 2 and 3 in the rotational symmetric SPIF of thermoplastics 
Fig. 9 Fracture of a-d PVC and e-h PC sheet in ISF with spindle non-rotating. a, b, e, f Fracture under plane strain state; $\mathbf{c}, \mathbf{d}, \mathbf{g}, \mathbf{h}$ fracture under biaxial strain state [88]
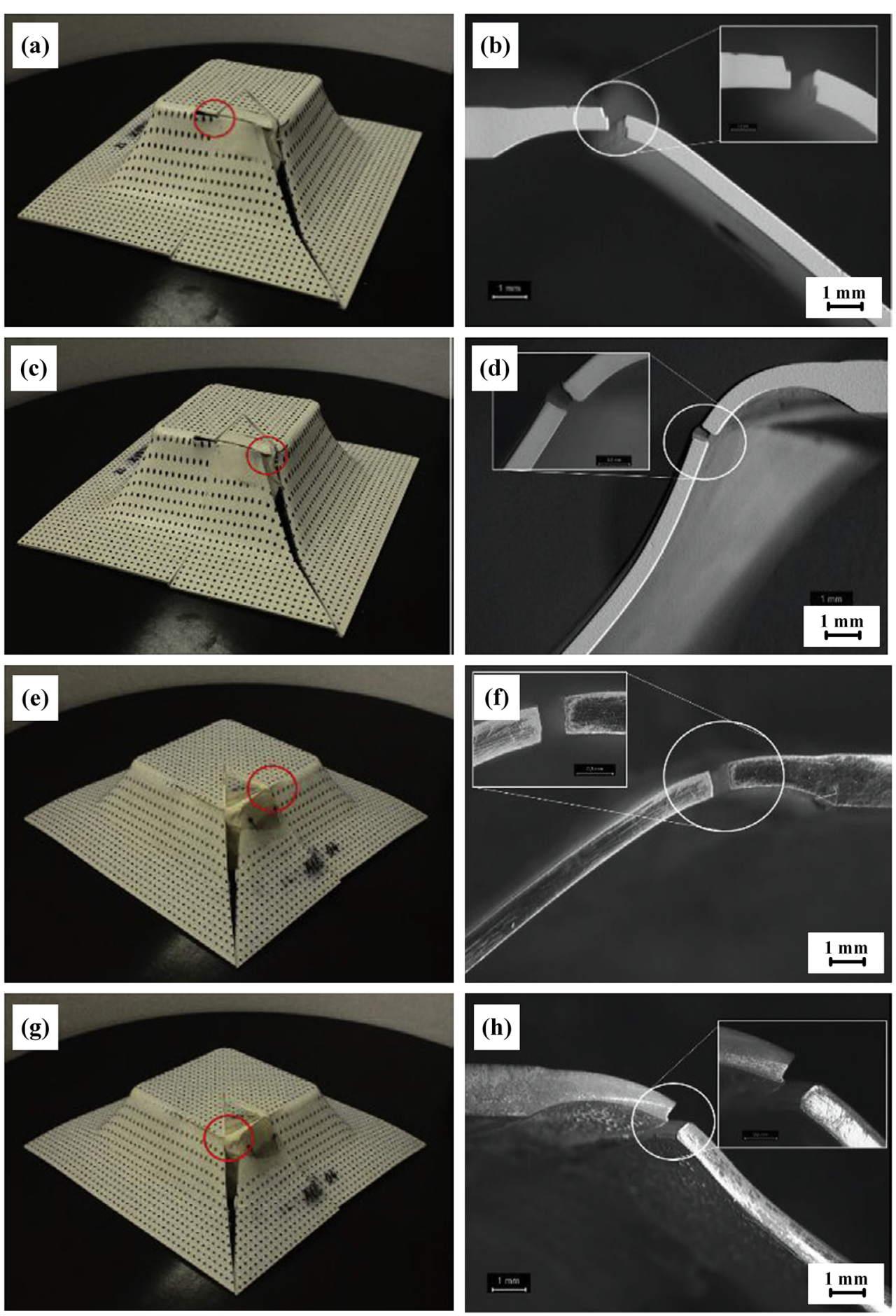

this usually observed behaviour into consideration, FFL, i.e. the FLD at necking, is not applicable to characterise the formability of thermoplastics in ISF. On the contrary, FFL, i.e. the FLD at fracture, is usually applied to describe the formability of thermoplastic materials in ISF. FLDs for ISF (FFL) and traditional forming technologies (FLC) are shown in Fig. 10 and FFL is always shaped like a straight line with a negative slope in the first quadrant of the FLD.
Martins et al. [25] attempted, for the first time, to employ FFL on the assessment of formability of thermoplastic materials in ISF. The authors did experiments in different strain paths through the tensile test, circular bulge and elliptical bulge to approach uniaxial, equi-biaxial and biaxial strain, respectively, to obtain the FFL of PVC, which is approximately a straight line with an analytical expression of $\varepsilon_{1}+0.28 \varepsilon_{2}=$ 0.74 , as shown in Fig. 11. In the process of extracting FFL, the 


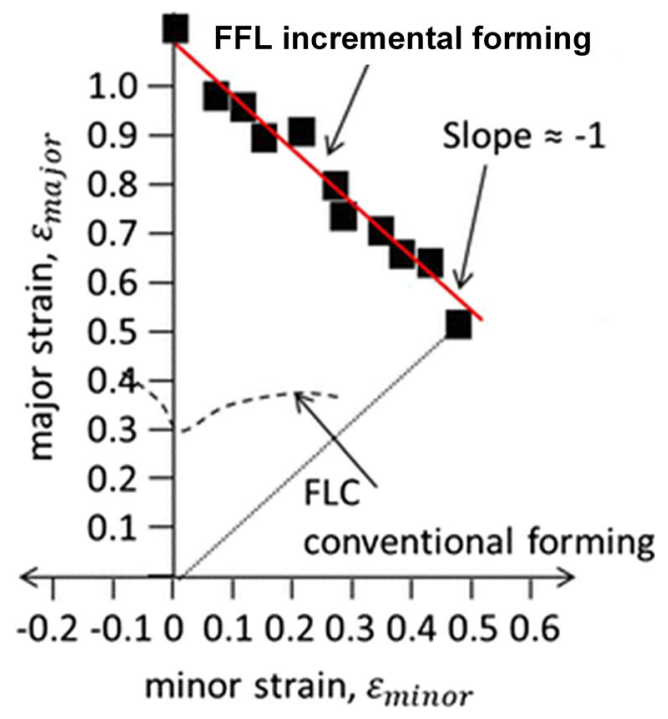

Fig. 10 Illustration of the forming limits of SPIF (labelled FFL) against that of the conventional forming process (labelled FLC) in the principal strain space $\left(\varepsilon_{1}, \varepsilon_{2}\right)[7]$

thickness at fracture is required to be measured so that the 'gauge length' strains (major true strain $\varepsilon_{1}$ and the minor true strain $\varepsilon_{2}$ ) can be obtained. Afterwards, the FFLs of PC, PVC, PA and PET were tested and obtained by Marques et al. [60], by using the methods described in detail in the publication of Silva et al. [75]. Subsequently, researchers found plane strain state, equi-biaxial strain state and biaxial strain state can be approached along different meridional paths of cone frustum and pyramid frustum with varying wall angle in ISF and thus Bagudanch et al. [88] conducted SPIF tests to obtain the FFLs for PVC, PC and PCL with spindle non-rotating, as shown in Fig. 12. The details are as follows: (1) the strain distribution on the outer surface of the formed thermoplastic sheet parts was measured off-line with the assistance of a 3D deformation digital measurement system via circle grid analysis; (2) the labelled Section $S_{0}$ is at the corner of the pyramid and closed to the equi-biaxial strain state; (3) Section $S_{1}$ is near the corner and refers to the biaxial strain state; (4) Section $S_{2}$ is on the flat surface and corresponds to the plane strain state.

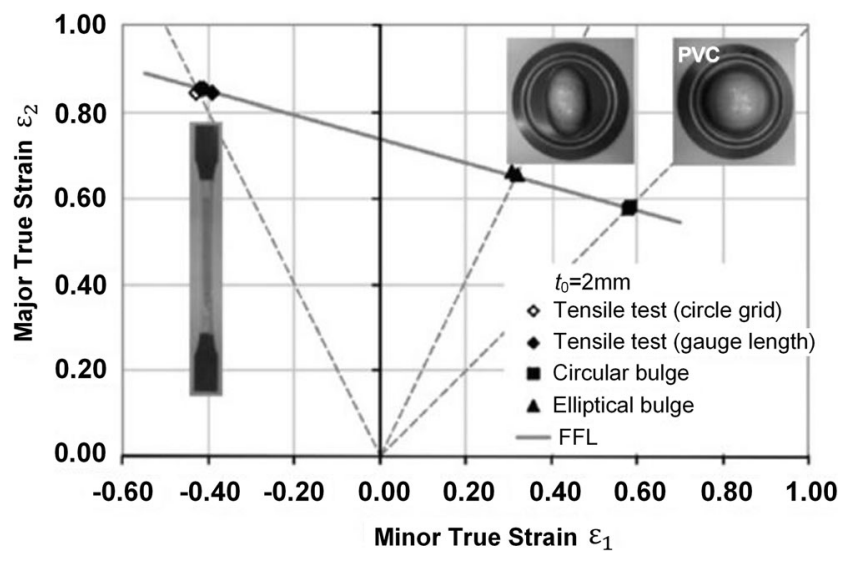

Fig. 11 FFL of PVC obtained by Martins et al. [25]

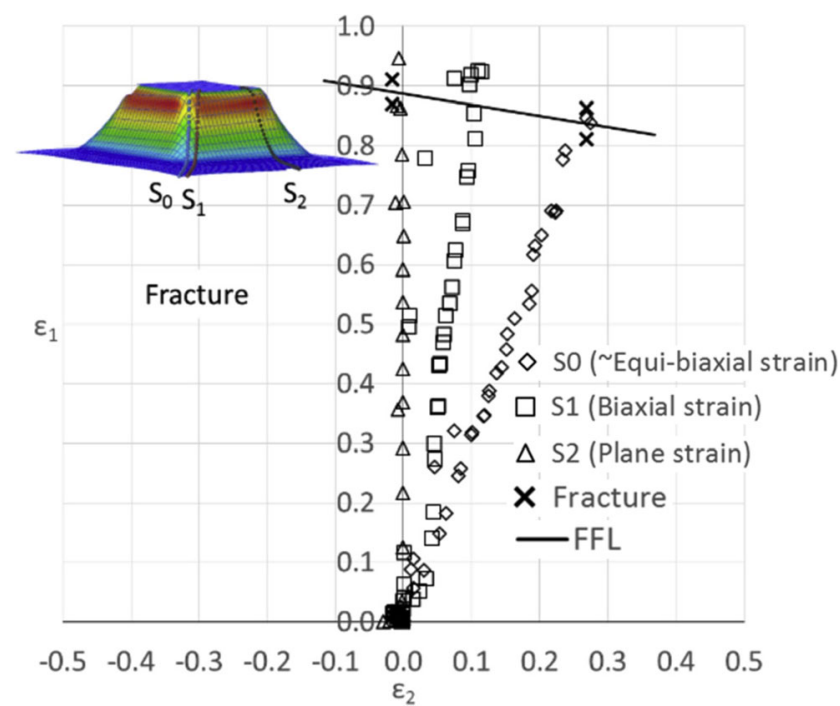

Fig. 12 FFL for PVC sheet with spindle non-rotating [88]

Apart from FFL, the formability of thermoplastic materials in ISF can also be characterised or indicated by the maximum forming depth [30] and the maximum drawing angle [67, 90]. When the maximum forming depth is used as a matric to describe the formability, as conducted by Bagudanch et al. [30], the part geometry, which is a pyramidal frustum with circular generatrix and changing wall angle, is always fixed in aspects of the length of pyramidal edges, initial wall angle, final wall angle and generatrix radius, while the parameters are variable to investigate their effects on the maximum forming depth, i.e. formability, of the thermoplastic materials in ISF. When the maximum drawing angle acts as an indication of the formability, the selected geometry of the part is fixed as well [67], except the condition in which the effect of initial drawing angle on the formability is focused on [25, 33].

\subsection{Effects of process parameters on formability}

As mentioned in Section 2.2, forming temperature, drawing angle, tool radius, step size and spindle speed are important process parameters, which affect the formability of thermoplastics in ISF.

\subsubsection{Forming temperature}

During the ISF process of thermoplastic materials, the material properties can be changed depending on the forming temperature because of its fundamental role in the material microstructure evolution and flow characteristics. Conte et al. [48] revealed the positive influence of process temperature on material formability in ISF of a thermoplastic-based composite reinforced by glass fibre. In their research, the formability, which is indicated by the final depth of shaped parts, is improved with the increase of forming temperature, no matter what combination of wall angle and step size. For the specific 
reason, Ambrogio et al. [57] found the thermoplastic sheets exhibit a super-plastic behaviour under elevated forming temperature, which allows significant strains improving the material formability. Apart from the pre-setting forming temperature, the friction heat can also lead to the temperature rise, which has an influence on the material formability of thermoplastics as well. Although several process parameters, such as tool radius and feed rate, could have influence on the friction between the tool and the workpiece, the major friction heat increase is generated from the spindle rotation and higher spindle speed. This will be discussed in Section 4.2.5.

\subsubsection{Initial drawing angle}

As a significant process parameter in ISF of thermoplastic materials, initial drawing angle $\Psi_{0}$ has been studied with important findings. In research of Martins et al. [25], with the increase of initial drawing angle, the formability (indicated by the maximum drawing angle) was decreased in ISF of PVC sheet. In another study of Silva et al. [33], for different thickness $(2 \mathrm{~mm}$ and $3 \mathrm{~mm}$ ) of PVC sheets, the trends of formability with the variation of initial drawing angle were the same as previous research. Other researchers found the above-mentioned influence of initial drawing angle on the formability of thermoplastics is not always applicable for all conditions. Marques et al. [60] drew a conclusion that the initial drawing angle $\Psi_{0}$ has an influence on the formability of thermoplastic materials only when varying from $30^{\circ}$ to $60^{\circ}$. Frazen et al. [26] revealed that with the increase of $\Psi_{0}$, the tendency of formability is different for different thermoplastics, even for different forming surface, as shown in Fig. 13. As observed by the authors, all thermoplastics, except POM, exhibited a significant variation in formability as initial drawing angle increases. For the majority of thermoplastic sheets investigated, the formability was decreased by the increased initial drawing angle, while for PVC sheet, the formability was improved with the increase of initial drawing angle when the rough surface with poor surface finish of the sheet was placed in contact with the forming tool. The trend is consistent with other thermoplastic sheets. However, when the shiny or smooth surface with good surface finish of the sheet was placed in contact with the forming tool, the formability was increased with the rise of initial drawing angle.

\subsubsection{Tool radius}

The formability of thermoplastic materials can be influenced by the shape of the forming tool [63], and more importantly by the tool radius. According to the studies by Marques et al. [60] and Martins et al. [25], it was found that the formability of thermoplastics in ISF is decreased with the increase of tool radius in ISF, which is consistent with the case of metallic material. However, in the research of Le et al. [23], the material formability exhibited a significant decrease when smaller tool radius was applied in the ISF of PP sheet with a thickness of $3 \mathrm{~mm}$. Similarly, when Silva et al. [33] investigated the influence of some important parameters, including tool radius, on the formability of PVC sheets in SPIF performed with benchmark cones with varying wall angle, the authors found the formability of PVC sheets with 3-mm initial thickness was increased with the increase of tool radius. It was an atypical behaviour shown by PVC sheets with 3-mm initial thickness but could be possibly explained by the reduced average level of meridional stress $\sigma_{\phi}$. In other studies by Formisano et al. [91] and Lambiase et al. [83], the formability of PC sheet with thickness of $1.4 \mathrm{~mm}$ and $1.9 \mathrm{~mm}$ was improved with the increase of the tool radius in tests of both a varying wall angle conical frusta and a pyramid frustum, and the same conclusion was obtained by Zhang et al. [90]. It can be concluded that the effect of tool radius is still debatable; some studies claim that large tool radius has a positive effect on the formability of thermoplastics, while other publications reveal that large tool radius has a negative effect.
Fig. 13 Formability (indicated by maximum drawing angle at failure) as a function of the initial drawing angle for sheet blanks with 2-mm thickness ( $5 \mathrm{~mm}$ tool radius) [26]. In the legend, PVC (1) is the shiny (smooth) surface of the sheet blank placed facing the forming tool; PVC (2) is the rough surface of the sheet blank placed facing the forming tool

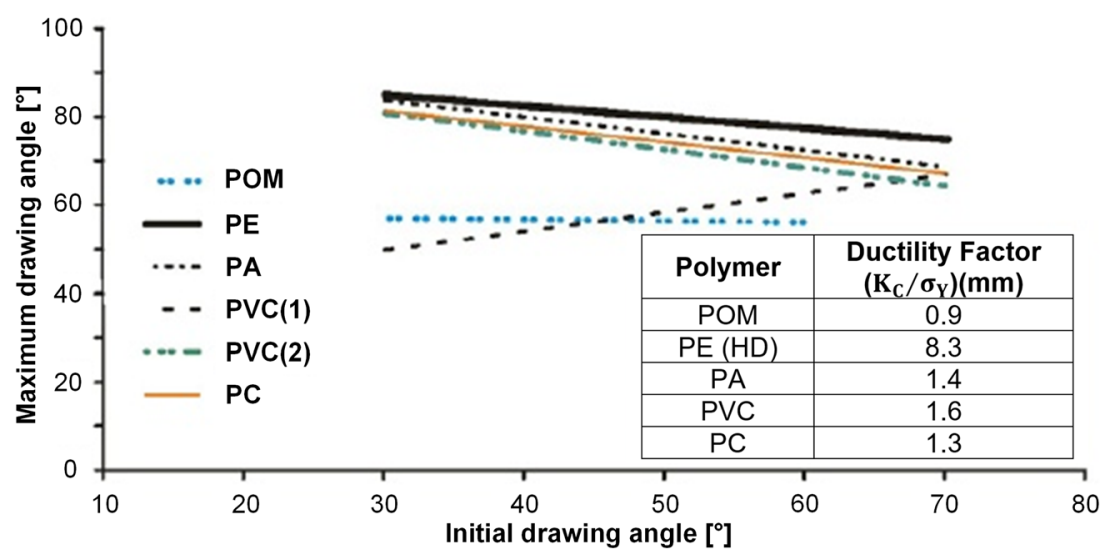




\subsubsection{Step size}

In ISF of metallic materials, the increased step size has a negative effect on the material formability [92]. For the cases of thermoplastic materials in ISF, the trend is not always the same. Le et al. [23] found the larger step size may lead to the increased formability of PP sheet in SPIF, which is the same with the metallic sheet. However, in the study of Bagudanch et al. [30], a larger step size leads to the increased formability in ISF process of PVC sheet, which is opposite from the regular behaviour of metals and other thermoplastics in ISF process. As the authors explained, the difference results from the rheological properties of thermoplastic materials [93]. Davarpanah et al. [67] found the above-mentioned positive influence of step size on formability of thermoplastics shows a limitation by the occurrence of wrinkle at excessively high step size, as indicated in Fig. 14.

\subsubsection{Spindle speed}

Spindle speed has a significant influence on the formability of thermoplastic materials in ISF. Many studies have been carried out to investigate the effects. Le et al. [23] indicated that the increased spindle speed can lead to improved formability of thermoplastics in ISF only when large tool radius, small step size or large feed rate is applied, which is the same with the major researches in the metallic system [13, 94, 95]. Bagudanch et al. [30, 88] also found the rise of spindle speed can contribute to the evaluation of material formability, which is indicated by the maximum forming depth and the limit major strain, while the formability becomes worse in the condition of free rotation. The influence results from the more generated friction heat on the contact tool-sheet surface and the temperature rise during the forming process. In detail, considering the failure modes, Davarpanah et al. [67] found the spindle speed has little influence on the formability with Mode 1 of failure but can drive the occurrence of wrinkle, which is consistent with the study findings of Le et al. [23].

\subsubsection{Initial sheet thickness}

As one of the significant parameters related to the formability in ISF of thermoplastic sheet, the initial thickness has been investigated in many studies. Most researchers believe that the material formability can be improved with the increase of the initial thickness, which is the same as the result in ISF of metallic sheet parts. In the studies of Martins et al. [25], Silva et al. [33], Marques et al. [60] and Bagudanch et al. [30], the thicker thermoplastic sheet was used, and the higher formability was obtained, no matter what indication (maximum drawing angle, with or without wrinkle) was used. Marques et al. [60] considered that the reason for the positive influence is the reduced stress triaxiality. However, some other researchers found the formability could be decreased with the increased initial sheet thickness, such as Franzen et al. [22] and Formisano et al. [91]. In terms of this issue, a final conclusion has not been made up to now and more indepth investigations should be carried out in the future.

\subsubsection{Combined effects of different parameters on formability}

As investigated by Le et al. [23], the decreased formability of PP sheet (indicated by the maximum drawing angle) can be caused by the increase of step size and feed rate. Particularly, when a larger step size was applied, its influence on the formability became extremely significant. The effects of interaction between tool radius and step size on the formability of thermoplastic materials were also found in this research. The combination of smaller tool radius and larger step size can lead to a decrease of formability. In another research by Hussain et al. [61], the formability of polymer is increased with the rising ratio between tool radius and initial sheet thickness, tool radius and step size or spindle speed and feed rate.

\section{Forming quality}

As ISF technology is application-oriented in such as medical fields, the forming quality plays an important role. Many researchers have investigated the forming qualities, including forming accuracy, surface finish and other factors, in ISF process of thermoplastic materials.

\subsection{Accuracy}

Forming accuracy refers to the geometrical/dimensional difference between the expected/set geometry and the formed thermoplastics part after ISF. In many cases, the reduction of forming accuracy results from the springback and twist.

Different methods to measure forming accuracy have been developed and the influential factors of forming accuracy have been investigated in previous literature. In the study of Durante et al. [70], the springback after the forming process was calculated by measuring the upward movement of the forming tool from the last region of the shaped part in contact with the tool until the vertical force became zero. The difference between the two vertical coordinates of the tool was considered the springback. The authors found the springback is significantly influenced by the tool type but negligibly influenced by toolpath strategy: the springback of the part shaped by the forming tool with a fixed end is lower than that in the condition of the rotating one, which generates lower friction force and smaller plastic strain in consequence. Besides, correction of the toolpath to overbend the thermoplastic sheet is also an effective method to reduce the springback and improve the forming accuracy, as revealed 
Fig. 14 Effect of step size on formability and failure modes for funnel-shaped PLA parts with radius of curvature a $10 \mathrm{~mm}, \mathbf{b} 12$ $\mathrm{mm}, \mathbf{c} 14 \mathrm{~mm}$ and d $16 \mathrm{~mm}$ [67]
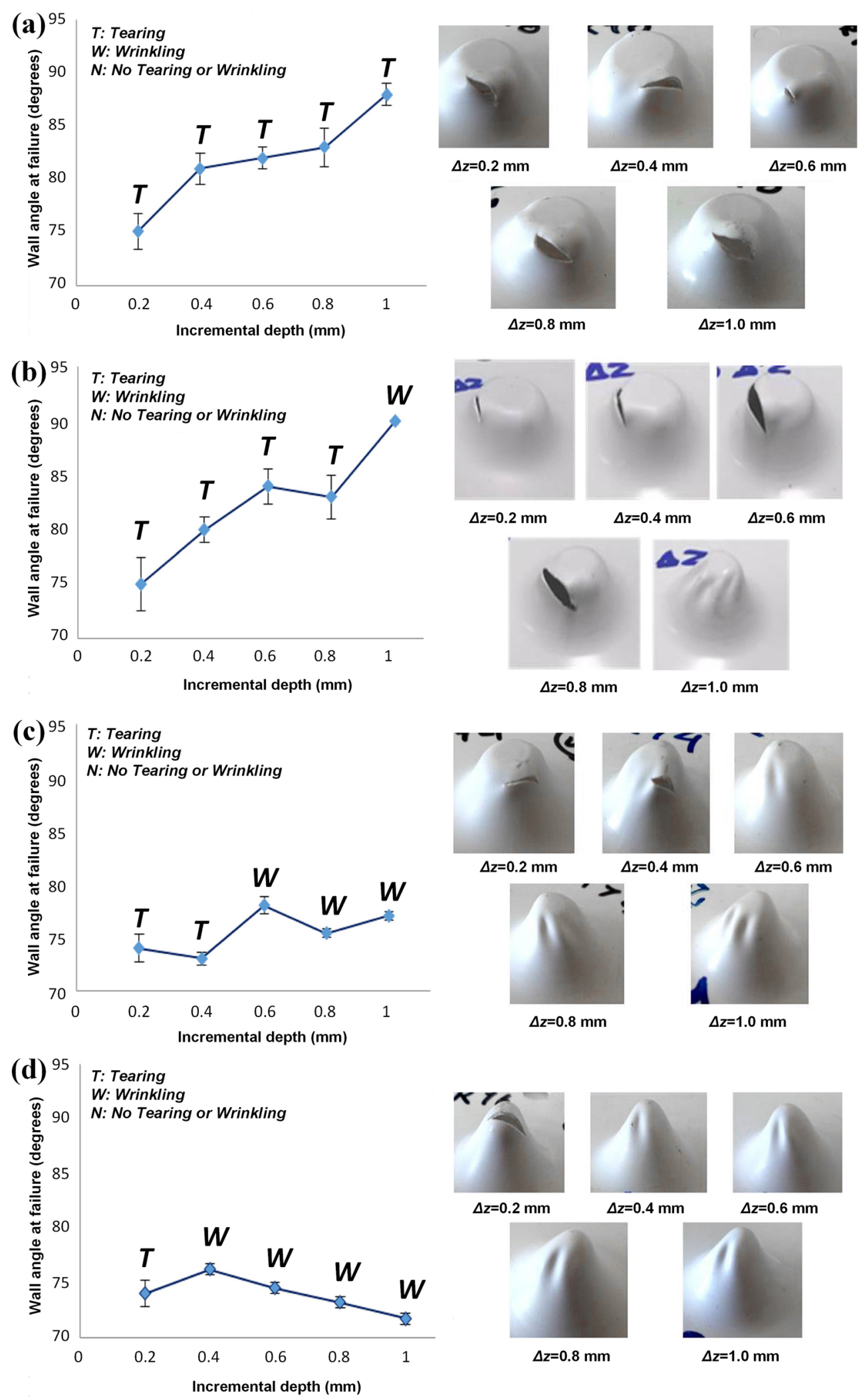
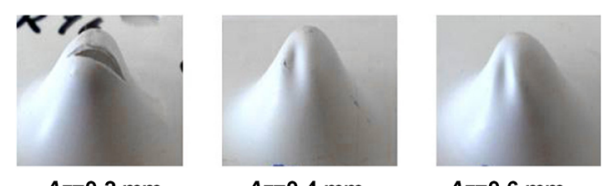

$\Delta z=0.6 \mathrm{~mm}$

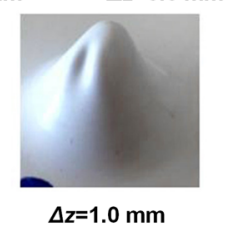

$\Delta \mathrm{z}=0.8 \mathrm{~mm}$

$\Delta z=1.0 \mathrm{~mm}$ and compared with the designed CAD file. The authors found the sheet part would recover once it was taken off from the clamping system because of the springback, but the accuracy by Maaß et al. [96]. Bagudanch et al. [36] used a portable 3D scanning system to obtain the real dimensions of the shaped parts after ISF of biocompatible PLC with thickness of $2 \mathrm{~mm}$ 
was still in an acceptable degree. However, this problem could be eliminated to a certain degree by heating the workpiece after forming without removal of the clamp, as investigated by Edwards et al. [66]. The authors also found increased step size can lead to reduced springback. Apart from the parameter step size, the study of Martins et al. [25] indicates that with the decrease of initial drawing angle $\Psi_{0}$ and increase of initial thickness of the sheet blanks, springback can be reduced, leading to the increased accuracy of the shaped parts. In the hot incremental sheet forming process of PC sheet, as investigated by Sridhar and Rajenthirakumar [59], the springback can be reduced to only $2 \%$ but the thinning of shaped parts is increased by $20 \%$. Further, the difference of springback between ISF of metallic and thermoplastic sheets was revealed by Al-Ghamdi [97]. In his study, besides the immediate elastic recovery as observed in ISF of metallic sheets, in ISF of thermoplastics, there is pronounced springback after an extended time. This results from the significant an-elasticity, i.e. elastic recovery over a wider time span, due to inherent phenomenal molecular processes. Lately, Yang and Chen et al. [84] argued that the twist has a critical effect on the geometric accuracy and more severe twist occurs in ISF of polymers than that of metals. The authors revealed the mechanism of twist experimentally and analytically, and proposed a new alternate spiral trajectory to restrain twist and eliminate wrinkle.

\subsection{Surface finish}

Compared with other responses, the study of the surface finish in ISF is scarce, for both metallic and thermoplastic parts, while it is quite important to ensure that the surface finish of final part manufactured by ISF is able to meet the requirements. The surface finish in ISF mainly refers to the surface roughness. In general, the quantitative measurement of the surface roughness is obtained with a profilometer by measuring the texture and topography of the surface. Only few researchers have studied the surface finish of final parts after ISF.

In general, the use of lubricant can improve the surface finish because the friction between the tool and the workpiece can be reduced. Commonly used types of lubricants in ISF of thermoplastics include grease [67, 81] and liquid lubricant $[29,36,49,58,61,70,80,88,91]$. Even water-soap emulsion can be used as lubricant $[22,25,33,56,60]$. Apart from appropriate lubricant, some forming parameters also have an influence on the surface roughness. In the study of Sabater et al. [72], the increased spindle speed and tool radius can lead to worse surface roughness because of the temperature rise due to the friction and the increased surface contact area and time period between the tool and the thermoplastic sheets. Thangavel et al. [27] also found a smaller roller ball tool with a diameter of $10 \mathrm{~mm}$ produces better surface finish compared with a larger one with a diameter of $16 \mathrm{~mm}$. According to the study of Bagudanch et al. [30], for the surface roughness of shaped parts, the most significantly influential parameters are the step size and the spindle speed. Besides, the interactions between the step size with the feed rate, the tool radius with the sheet thickness and the feed rate with the spindle speed play an important role as well. Among the above parameters, the negative influence of increased step size is expected because at a larger step down the generated tool path will slightly differ from the geometry profile due to the interpolation. For example, in using a tool diameter of $6 \mathrm{~mm}$ at a feet rate of $1500 \mathrm{~mm} / \mathrm{min}$ without spindle rotation, a surface roughness $\left(R_{\mathrm{a}}\right)$ of $0.422 \mu \mathrm{m}$ was achieved with a step size of $0.5 \mathrm{~mm}$. This is compared to a surface roughness of $0.321 \mu \mathrm{m}$ with a step size of $0.2 \mathrm{~mm}$ in ISF of a 2-mm-thick sheet. Also, as the increase of spindle speeds, the surface roughness increases due to the temperature rise resulting from the friction heat when the forming temperature is close to the glass transition temperature. However, in the study of Medina-Sanchez et al. [31], the roughness of parts formed with the steel tool decreases as the increase of the spindle speed, mainly because the forming temperature is lower than the glass transition temperature. The authors also found that, for parts formed using the aluminium tool, surface roughness is significantly lower than that obtained with the steel tool. Using an aluminium tool to form a thermoplastic part can lead to almost changeless roughness compared with the original sheet. Besides the tool material, surface roughness can also be influenced by tool types and tool paths. High surface quality can be guaranteed by both tool types and tool paths [70].

\subsection{Other consideration factors}

Environmental and sustainability issues have become an important consideration in the whole field of manufacturing research. For ISF technology, it is important to consider economic cost and energy consumption during the manufacturing process.

\subsubsection{Economic cost}

Bagudanch et al. [68] studied the effects of different parameters on the cost in ISF and gave the relationships between them. Apart from this, a complete and accurate method to estimate the cost during ISF was proposed by Branker et al. [98]. This method is suitable for both metal parts and thermoplastic parts, taking the forming costs $\left(C_{\mathrm{f}}\right)$, the setup costs $\left(C_{\mathrm{s}}\right)$, the workpiece handling costs $\left(C_{1}\right)$, the tooling costs $\left(C_{\mathrm{t}}\right)$, the direct material costs $\left(C_{\mathrm{MD}}\right)$, the indirect material costs $\left(C_{\mathrm{MID}}\right)$, the energy consumed during the process $\left(C_{\mathrm{ED}}\right)$, the ancillary energy $\left(C_{\mathrm{EA}}\right)$ and the environmental burden $\left(C_{\text {env }}\right)$, into consideration. For simple geometries, the above method is effective to calculate the cost of ISF because it considers not only the raw materials and manufacturing time but also the 
environmental impact, but for a customised shape, an additional design cost $\left(C_{\text {design }}\right)$ should be included. Also, the trimming cost $\left(C_{\mathrm{cut}}\right)$ and the cost for biomodel fabrication $\left(C_{\mathrm{bm}}\right)$ also need to be considered [38]. Therefore, the cost for a customised part manufactured by SPIF $\left(C_{\mathrm{SPIF}}\right)$ may be estimated by the following equation:

$$
\begin{aligned}
C_{\mathrm{SPIF}}= & \mathrm{C}_{\mathrm{f}}+\mathrm{C}_{\mathrm{s}}+\mathrm{C}_{1}+C_{\mathrm{t}}+C_{\mathrm{MD}}+C_{\mathrm{MID}}+C_{\mathrm{ED}} \\
& +C_{\mathrm{EA}}+C_{\text {env }}+C_{\text {design }}+C_{\mathrm{cut}}+C_{\mathrm{bm}}
\end{aligned}
$$

If TPIF is used to manufacture the customised part, the die manufacturing cost $\left(C_{\mathrm{die}}\right)$ should be included to estimate the cost for TPIF $\left(C_{\mathrm{TPIF}}\right)$, as shown in the following equation:

$C_{\mathrm{TPIF}}=C_{\mathrm{SPIF}}+C_{\mathrm{die}}$

The above-mentioned approach is mainly about the total cost used in the manufacturing process of a certain shape.

\subsubsection{Energy consumption}

In addition to the economic cost, energy consumption can be reduced by optimising the process parameters. Bagudanch et al. [68] investigated the effects of some process parameters on energy consumption in SPIF of PC and PVC. According to their research, the increase of step down and the feed rate and the decrease in the spindle speed lead to decreased energy consumption. An empirical equation to estimate the energy consumption used in SPIF $(E)$ was proposed in the following equation, specifically for the Kondia HS1000 3-axis milling machine used in the research.

$E=(2854.6+0.592 S) T$

where $S$ is the spindle speed in revolutions per minute and $T$ is the forming time in second. The error of energy consumption estimated by the proposed empirical equation is always less than $10 \%$ compared with the value measured in experiments. Another important influence factor on energy consumption is the external heating sources used in heat-assisted ISF. The use of the external heating device, i.e. the pre-set forming temperature, can raise the cost, which is the same as that in the metallic system [18]. Therefore, to avoid using external heat to conduct ISF of thermoplastics at room temperature is an effective way to reduce the energy consumption of the process, but this should be based on the premise that the satisfactory parts can be obtained. To summarise, the cost and energy consumption can be obtained by using analytical or empirical equations. More importantly, the cost and energy consumption can be reduced by optimising the process parameters.

\section{Discussions}

ISF technology has been studied to form thermoplastic materials for over 10 years and gained increasing attention in recent years. The rapid development of this research field mainly results from the combined advantages of the technology itself (improved material formability, good geometric accuracy and other benefits in manufacturing small-batch and customised non-axisymmetric sheet parts) and promising thermoplastic materials. A number of key areas in ISF of thermoplastics are discussed in the following sections.

\subsection{Processing conditions}

The process setup for ISF of thermoplastic materials is almost the same as the setup used in the metallic system. The elevated temperature is effective to improve the formability of thermoplastic sheets in ISF, and a heating system, using a heating source such as electric resistance, a halogen lamp or a heating coil, can be embedded into the ISF machine to form workpieces with higher forming accuracy. However, an external heating source is not definitely necessary given the condition that the thermoplastics have good material formability and the friction heat could be used to soften the material, although the effect of friction heat is still debatable because it may damage the surface quality of workpiece. Therefore, both the pre-set heat and the friction heat have their own advantages and shortcomings. The external heat could greatly improve the material formability and forming quality in ISF but cause lower strength of the formed part and more energy use and cost, while the friction heat could help save energy and increase the formability to a certain extent but affect the surface finish of the formed part.

Apart from forming temperature, initial drawing angle, tool radius, step size, spindle speed and initial sheet thickness are important parameters in ISF of thermoplastics. All of these parameters have considerable influence on the formability and other aspects of forming quality. Higher forming temperature and spindle speed can cause reduced surface quality, and larger step size can lead to excessive thinning and high surface roughness. In addition, the above parameters have an influence on the forming force, which gives an indication in selecting a suitable machine and using a specific tool.

\subsection{Deformation and failure mechanism}

The highly localised plastic forming is a distinctive feature of ISF compared with other traditional sheet plastic forming processes and stretching leading to membrane strain is the dominant deformation mode. For ISF of thermoplastic materials, there are three basic deformation modes including plane strain stretching on flat surfaces, plane strain stretching on rotational symmetric surfaces and equi-biaxial stretching at corners. 
Currently, a theoretical framework of membrane analysis is mainly used to investigate the deformation mechanism in ISF of thermoplastics although some material constitutive models have been developed. In ISF, the stress and strain states in the small localised plastic zone of thermoplastics show a significant difference from that of metals. The microstructure evolution under deformation is also complicated with the changes of micro void density, degree of crystallinity, crystal and chain orientation.

Under the ISF deformation, there are three proposed failure modes in ISF of thermoplastic materials, including in-plane fracture by ductile tearing along the circumferential direction at the transition area between the inclined wall and the corner, wrinkle along the inclined wall in the proximity of the corner and oblique fracture in the bisector direction of the circumferential-meridional surface on the wall. Among the above failure modes, the last two are unique to the ISF of thermoplastics. During the fracture process, no obvious necking, i.e. suppressed necking, is considered an important feature.

\subsection{Formability}

The formability of thermoplastic sheets in ISF exhibits significant improvement compared with other plastic forming technologies. Basically, FFL, i.e. the FLD at fracture, is utilised to characterise the formability of thermoplastic sheet in ISF. FFL is comprised of a straight line with a negative slope in the first quadrant of the FLD. The uniaxial, equi-biaxial, biaxial strain and plane strain can be obtained by some traditional tests including tensile test, circular bulge and elliptical bulge, or in different meridional paths of cone and pyramid frustums with varying wall angle in ISF under the above-mentioned three deformation modes. Besides FFL, the maximum forming depth and the maximum drawing angle can also be used as metrics of formability.

In general, for the majority of thermoplastics, the increased formability in ISF can be approached with the higher forming temperature and spindle speed (leading to more friction heat), while there remains controversy about the effect of initial drawing angle, tool radius, step size and initial sheet thickness on the formability. For the majority of thermoplastic materials, with the increase of initial drawing angle, the formability is increased, but there are some exceptions such as POM, and PVC sheet with the smooth surface placed facing the forming tool as described in Section 4.2.2 [26]. The positive effect of decreased tool radius, step size and increased initial sheet thickness on the improvement of formability is not always suitable as well. An appropriate combination of different parameters is also important to the formability. The combination of larger step size and larger feed rate and the combination of smaller tool radius and larger step size can lead to the decreased formability, while the combination of larger tool radius and smaller initial sheet thickness and the combination of larger spindle speed and smaller feed rate can improve the formability.

\subsection{Forming quality}

The forming accuracy can be measured by using a portable 3D scanning system, coordinate measuring machine to calculate the moving distance of forming tool. The main reason for the poor forming accuracy is springback, including immediate elastic recovery and an-elastic recovery after an extended time span. The springback can be reduced by appropriate tool type, toolpath strategy, decreased initial drawing angle, increased initial sheet thickness or elevated forming temperature.

The surface roughness of shaped thermoplastic workpieces can be quantitatively obtained with a profilometer by measuring the texture and topography. In general, the better surface finish can be approached with slower spindle speed, tool radius and step size as well as suitable tool material, type and path.

\subsection{Effects of process parameters on ISF of thermoplastics}

The effects of different parameters on the formability of thermoplastic materials are summarised based on the above literature review in order to provide readers with clearer information to refer to. The detailed results are given in Table 2 with the effects of process parameters and corresponding publications.

Table 2 is comprised of the parameters, forming temperature, initial drawing angle, tool radius, step size, spindle speed and initial sheet thickness, and their effects on the forming force, formability, forming accuracy, surface finish and energy and cost. The up arrow $(\uparrow)$ or down arrow $(\downarrow)$ behind the parameters means the increase or decrease of this parameter. Similarly, the up arrow $(\mathbb{\imath})$, down arrow ( $)$ or horizontal bar ( $\Rightarrow$ ) in the cells for resulting effects represents the positive, negative or no influence on them.

From Table 2, although most process parameters are reported to have the same effect in ISF of thermoplastics from referenced publications, it is still debatable on the effect of tool radius, step size, initial sheet thickness on the formability as introduced above. The effect of spindle speed on the forming accuracy and the effect of tool radius on the surface finish are not commonly acknowledged. Although a possible explanation is the difference in mechanical and physical properties among different thermoplastics, further work should be done to understand the detailed reasons. 
Table 2 Effects of process parameters on different aspects of ISF of thermoplastics from reviewed publications

\begin{tabular}{|c|c|c|c|c|c|}
\hline \multirow[t]{2}{*}{ Process parameters } & \multicolumn{5}{|l|}{ Resulting effects } \\
\hline & Forming force & Formability & Accuracy & Surface finish & Energy and cost \\
\hline Forming temperature $\uparrow$ & 仓ิ [30] & 仓 $[30,88]$ & $\hat{\Perp}[31,59]$ & \& [31] & \\
\hline Initial drawing angle $\downarrow$ & & 仓 $[25,33]$ & $\hat{\imath}[25]$ & & \\
\hline Tool radius $\downarrow$ & ת $[30,68,72]$ & $\begin{array}{l}\text { 仓 }[25,60] \\
\text { ป }[22,23,30,33,68,83,91]\end{array}$ & & $\begin{array}{l}\text { 仓 }[22,27] \\
\square[68]\end{array}$ & ㅁ [68] \\
\hline Step size $\uparrow$ & 仓 $[30,67,68]$ & $\begin{array}{l}\text { 仓 }[30,67,68] \\
\text { ป }[23]\end{array}$ & 仓 [66] & ת $[30,68]$ & \& $[68]$ \\
\hline Spindle speed $\uparrow$ & $\sqrt{\Omega}[30,31,67,72]$ & 仓 $[23,30,68,88]$ & $\begin{array}{l}\hat{\Perp}[37,38] \\
\therefore[66]\end{array}$ & ת $[30,31,58,68]$ & $\hat{\imath}[68]$ \\
\hline Initial sheet thickness $\uparrow$ & 仓 $[30,34,68]$ & $\begin{array}{l}\text { 仓 }[25,30,33,60,68] \\
\text { ป }[22,83,91]\end{array}$ & $\hat{u}[25]$ & ת [68] & ㅁ [68] \\
\hline
\end{tabular}

\subsection{Comparison between ISF of thermoplastic and metallic materials}

Although ISF of thermoplastic materials is similar with the condition in the metallic system in aspects of process setup, formability evaluation methods and the influence of different parameters on forming quality, the material behaviour is quite different from thermoplastics to metals. Therefore, there is a particular need to identify and understand important differences between ISF of thermoplastic and metallic materials. Based on the review of published work, the main differences are summarised in Table 3.

In thermoplastic system, the initial drawing angle, of which the effect on formability has never been studied in the metallic system, is considered a parameter and has an important influence on the formability of thermoplastic sheet in ISF. Also, the influence of tool radius and step size on the formability of different thermoplastics is not the same. Some of them are identical to metals while there remain some exceptions. In terms of the deformation mechanism, the relevant investigation is mainly focused on the membrane analysis with pressure-sensitive yield surface in ISF of thermoplastics, but other mechanisms including through-thickness shear deformation and bending under tension have been widely studied in metallic system. Even only for the membrane analysis, the stress and strain states in the small localised plastic zone are different in these two systems. In terms of failure behaviour, in-plane fracture is generally observed in ISF of both thermoplastics and metals, while wrinkle and oblique fracture are unique failure modes for thermoplastic sheets. For

Table 3 Differences between ISF of thermoplastic and metallic materials

\begin{tabular}{|c|c|c|}
\hline Research aspect & Thermoplastics & Metals \\
\hline Process parameters & $\begin{array}{l}\text { Initial drawing angle acts as a parameter. Maximum drawing } \\
\text { angle acts as a metric of formability }\end{array}$ & $\begin{array}{l}\text { Maximum drawing angle is a parameter to determine the } \\
\text { formability }\end{array}$ \\
\hline \multirow{3}{*}{$\begin{array}{l}\text { Effects of process } \\
\text { parameters on } \\
\text { formability } \\
\text { Deformation } \\
\text { mechanism }\end{array}$} & $\begin{array}{l}\text { (1) Majority exhibits decreased formability with increased tool } \\
\text { radius while there are some exceptions. } \\
\text { (2) The effect of step size on formability depends on the material. }\end{array}$ & $\begin{array}{l}\text { (1) Formability decreases with increased tool radius. } \\
\text { (2) Formability decreases with an increased step size. }\end{array}$ \\
\hline & $\begin{array}{l}\text { (1) Membrane analysis with pressure-sensitive yield surface is } \\
\text { mainly investigated. }\end{array}$ & $\begin{array}{l}\text { (1) Membrane analysis, through-thickness shear } \\
\text { deformation and tension under bending are widely } \\
\text { investigated }\end{array}$ \\
\hline & \multicolumn{2}{|c|}{ (2) Stress and strain states in the small localised plastic zone are different. Details are shown in Table 1.} \\
\hline Failure behaviour & $\begin{array}{l}\text { (1) Failure Mode } 2 \text { and } 3 \text {, i.e. wrinkle and oblique fracture, are } \\
\text { unique to thermoplastic materials. } \\
\text { (2) No obvious necking occurs before fracture. }\end{array}$ & $\begin{array}{l}\text { (1) Failure Mode 1, i.e. in-plane fracture, is generally } \\
\text { observed. } \\
\text { (2) Fracture with or without necking depends on the } \\
\text { material. }\end{array}$ \\
\hline Forming accuracy & $\begin{array}{l}\text { (1) The springback results from not only immediate elastic } \\
\text { recovery but also an elastic recovery after an extended time } \\
\text { span. } \\
\text { (2) More severe twist occurs in ISF of thermoplastics than that of }\end{array}$ & $\begin{array}{l}\text { (1) The springback is only caused by immediate elastic } \\
\text { recovery. } \\
\text { metals. }\end{array}$ \\
\hline
\end{tabular}


forming accuracy, immediate elastic recovery causes springback and poor forming accuracy in both these two systems, but there is additional an-elastic recovery after a long time after ISF of thermoplastic sheets. Finally, in ISF of thermoplastics, the twist is more serious compared with that in ISF of metals.

\section{Research challenges and future directions}

Although ISF has been extensively researched to form metal sheet parts, the application of ISF on thermoplastic sheets is still at an early stage. In this paper, the authors attempted to provide a summary of the recent advances, discussions on the key scientific issues in ISF of thermoplastic materials. This provides a basis for observation of research challenges and future directions.

Research challenges:

(1) There is little research on phenomenological or physical constitutive and damage models to describe and predict the material behaviour of thermoplastics in the ISF process with relatively high precision. The physical mechanism behind the material behaviour of thermoplastics, such as strain softening and strain hardening, has not been fully understood particularly under the ISF deformation conditions.

(2) The analytical mechanics are relatively complicated when membrane analysis with pressure-sensitive yield surface is used. If other mechanisms, such as throughthickness shear deformation and bending under tension, are taken into consideration, the case is even much more complicated, especially for thermoplastic materials.

(3) The current analytical framework of ISF of thermoplastic materials is mainly focused on the deformation mechanics associated with Failure Mode 1. It is difficult to apply this analytical framework to develop and investigate the deformation mechanics behind Failure Modes 2 and 3.

(4) In heat-assisted ISF of thermoplastics, the heat source is normally set under the sheet, leading to a higher temperature on the bottom surface than the top surface of the sheet. It would be a challenge to achieve a uniform temperature distribution through the thickness.

Future directions:

(1) So far, little attention has been paid in numerical simulation for ISF of thermoplastic materials, which is an important research aspect. The thermo-mechanical FE simulation should be carried out to investigate the deformation mechanism, fracture behaviour and forming quality in ISF of thermoplastic materials.
(2) The capability for failure prediction of thermoplastic materials in ISF using either simulation or analytical method is of considerable benefits. Future work should be focused on the development of numerical simulation and analytical method to predict failure of thermoplastics in ISF.

(3) It is highly desirable to develop a new model to capture the effect of temperature and strain rate rise of sheet during SPIF of thermoplastics. This could be employed to evaluate the stresses in heat-assisted ISF of thermoplastics.

(4) There is a need to construct the forming limit curve (FLC) at fracture for some important types of biocompatible thermoplastics, e.g. polyetheretherketone (PEEK) and PMMA sheets, by using such as Nakajima test so as to apply different strain paths in stretching. The constructed FLC would be beneficial in predicting fracture in SPIF of these biocompatible thermoplastics.

(5) The effect of strain softening and strain hardening in thermoplastics on the deformation and fracture mechanisms is yet to be fully established. Future research should take strain softening and strain hardening effects into consideration in looking into the deformation and fracture behaviour of thermoplastics in ISF.

(6) Through-thickness shear deformation and bending under tension in ISF of thermoplastic materials lack investigation. Future work should be carried out in taking through-thickness shear deformation and bending under tension of thermoplastics into consideration in either simple deformation or ISF.

(7) The fracture mode of thermoplastic materials in ISF is different from that under quasi-static tensile test: there is no significant necking before fracture. Future work should try to reveal the mechanism for the phenomenon.

(8) Little work has been reported on the mechanical properties and microstructural changes of thermoplastic materials in ISF. Future research should pay more attention to the mechanical properties and microstructural evolution of thermoplastics during ISF process.

(9) Future research should be devoted to exploring the possibility of ISF of other kinds of materials with application prospects, such as polymer-based composite materials, bilayer and multilayer sheets and the optimised methods to form these types of materials using ISF.

(10) High temperature can improve the accuracy of the shaped part but may increase the surface wear, leading to increased surface roughness. The balance between temperature and surface roughness should be investigated.

(11) The influence of tool radius, step size and initial sheet thickness on the formability of thermoplastic materials is not always identical for different thermoplastics with some exceptions. Future work should be carried out to study such exceptional conditions. 
(12) A more comprehensive parametric study can be beneficial to investigate the interdependence and interaction between these parameters and to achieve the optimum outcomes of formability and other aspects of forming quality.

Acknowledgments The first author gratefully thanks the financial support of Faculty of Engineering Research Excellence PhD Scholarship awarded by the University of Nottingham. The authors also acknowledge Dr Shakir Gatea from the University of Kufa for invaluable discussions.

Open Access This article is licensed under a Creative Commons Attribution 4.0 International License, which permits use, sharing, adaptation, distribution and reproduction in any medium or format, as long as you give appropriate credit to the original author(s) and the source, provide a link to the Creative Commons licence, and indicate if changes were made. The images or other third party material in this article are included in the article's Creative Commons licence, unless indicated otherwise in a credit line to the material. If material is not included in the article's Creative Commons licence and your intended use is not permitted by statutory regulation or exceeds the permitted use, you will need to obtain permission directly from the copyright holder. To view a copy of this licence, visit http://creativecommons.org/licenses/by/4.0/.

\section{References}

1. Hussain G, Khan HR, Gao L, Hayat N (2013) Guidelines for toolsize selection for single-point incremental forming of an aerospace alloy. Mater Manuf Process 28(3):324-329

2. Duc-Toan N, Seung-Han Y, Dong-Won J, Tae-Hoon C, YoungSuk K (2011) Incremental Sheet metal forming: numerical simulation and rapid prototyping process to make an automobile whitebody. Steel Res Int 82(7):795-805

3. Jeswiet J, Micari F, Hirt G, Bramley A, Duflou J, Allwood J (2005) Asymmetric single point incremental forming of sheet metal. CIRP Ann Manuf Technol 54(2):623-649

4. Ham M, Jeswiet J (2008) Single point incremental forming. Int J Mater Prod Technol 32(4):374-387

5. Echrif SBM, Hrairi M (2011) Research and progress in incremental sheet forming processes. Mater Manuf Process 26(11):1404-1414

6. Behera AK, de Sousa RA, Ingarao G, Oleksik V (2017) Single point incremental forming: an assessment of the progress and technology trends from 2005 to 2015. J Manuf Process 27:37-62

7. Duflou JR, Habraken A-M, Cao J, Malhotra R, Bambach M, Adams D, Vanhove H, Mohammadi A, Jeswiet J (2017) Single point incremental forming: state-of-the-art and prospects. Int $\mathrm{J}$ Mater Form 11(6):743-773

8. Li YL, Chen XX, Liu ZB, Sun J, Li FY, Li JF, Zhao GQ (2017) A review on the recent development of incremental sheet-forming process. Int J Adv Manuf Technol 92(5-8):2439-2462

9. Ajay CV, Boopathi C, Kavin P (2019) Incremental sheet metal forming (ISMF): A literature review, AIP Conference Proceedings, AIP Publishing LLC, p 030012

10. Tisza M (2012) General overview of sheet incremental forming. J Achiev Mater Manuf Eng 55(1):113-120

11. Sevsek L, Pepelnjak T (2019) The review of the achievements in the field of incremental forming. Res Sci Today 17:124

12. Emmens WC, van den Boogaard AH (2009) An overview of stabilizing deformation mechanisms in incremental sheet forming. J Mater Process Technol 209(8):3688-3695
13. McAnulty T, Jeswiet J, Doolan M (2017) Formability in single point incremental forming: a comparative analysis of the state of the art. CIRP J Manuf Sci Technol 16:43-54

14. Emmens WC, Sebastiani G, van den Boogaard AH (2010) The technology of incremental sheet forming-a brief review of the history. J Mater Process Technol 210(8):981-997

15. Kumar A, Gulati V, Kumar P, Singh H (2019) Forming force in incremental sheet forming: a comparative analysis of the state of the art. J Braz Soc Mech Sci Eng 41(6):251

16. Ai S, Long H (2019) A review on material fracture mechanism in incremental sheet forming. Int J Adv Manuf Technol 104(1-4):3361

17. Taleb-Araghi B, Goettmann A, Bambach M, Biermann T, Hirt G, Weisheit A (2010) Development of hybrid incremental sheet forming processes. Steel Res Int 81(9):918-921

18. Liu ZB (2018) Heat-assisted incremental sheet forming: a state-ofthe-art review. Int J Adv Manuf Technol 98(9-12):2987-3003

19. Peng W, Ou H, Becker A (2019) Double-sided incremental forming: a review. J Manuf Sci Eng 141(5) 050802-050802-12

20. Dewang Y, Tenguria N, Sharma V, Dubey MK (2019) Formation of hole flanges through incremental forming: a review, Advances in Engineering Design. Springer, Singapore, pp 547-561

21. Gatea S, Ou HG, McCartney G (2016) Review on the influence of process parameters in incremental sheet forming. Int J Adv Manuf Technol 87(1-4):479-499

22. Franzen V, Kwiatkowski L, Martins PAF, Tekkaya AE (2009) Single point incremental forming of PVC. J Mater Process Technol 209(1):462-469

23. Le VS, Ghiotti A, Lucchetta G (2008) Preliminary studies on single point incremental forming for thermoplastic materials. Int J Mater Form 1:1179-1182

24. Rajenthirakumar D, Sridhar R (2014) Single point incremental sheet forming of polymer on Computer Numerically Controlled (CNC) milling machine tool, Key Engineering Materials, Trans Tech Publ, pp 420-426

25. Martins PAF, Kwiatkowski L, Franzen V, Tekkaya AE, Kleiner M (2009) Single point incremental forming of polymers. CIRP Ann Manuf Technol 58(1):229-232

26. Franzen V, Kwiatkowski L, Neves J, Martins P, Tekkaya A (2008) On the capability of single point incremental forming for manufacturing polymer sheet parts, ICTP2008, 9th International Conference on Theory of Plasticity

27. Thangavel K, Duraiswamy R, Nagarajan S, Ramasamy S (2019) Influence of roller ball tool in single point incremental forming of polymers. Tehnički vjesnik 26(1):171-176

28. Sridhar R, Rajenthirakumar D (2016) Incremental forming of polymer-numerical and experimental investigation. Polym Polym Compos 24(7):489-498

29. Yonan SA, Silva MB, Martins PAF, Tekkaya AE (2014) Plastic flow and failure in single point incremental forming of PVC sheets. Express Polym Lett 8(5):301-311

30. Bagudanch I, Garcia-Romeu ML, Centeno G, Elias-Zuniga A, Ciurana J (2015) Forming force and temperature effects on single point incremental forming of polyvinylchloride. J Mater Process Technol 219:221-229

31. Medina-Sánchez G, Torres-Jimenez E, Lopez-Garcia R, DoradoVicente R, Cazalla-Moral R (2017) Temperature influence on single point incremental forming of PVC parts. Procedia Manuf 13: 335-342

32. Pradella MP, Folle LF (2016) Study of incremental sheet forming process of PVC. Materia 21(4):1094-1104

33. Silva MB, Alves LM, Martins PAF (2010) Single point incremental forming of PVC: Experimental findings and theoretical interpretation. Eur J Mech A Solids 29(4):557-566

34. Yonan SA, Soyarslan C, Haupt P, Kwiatkowski L, Tekkaya AE (2013) A simple finite strain non-linear visco-plastic model for 
thermoplastics and its application to the simulation of incremental cold forming of polyvinylchloride (PVC). Int J Mech Sci 66:192201

35. Centeno G, Morales-Palma D, Gonzalez-Perez-Somarriba B, Bagudanch I, Egea-Guerrero JJ, Gonzalez-Perez LM, GarciaRomeu ML, Vallellano C (2017) A functional methodology on the manufacturing of customized polymeric cranial prostheses from CAT using SPIF. Rapid Prototyp J 23(4):771-780

36. Bagudanch I, Lozano-Sánchez LM, Puigpinós L, Sabater M, Elizalde LE, Elías-Zúñiga A, Garcia-Romeu ML (2015) Manufacturing of polymeric biocompatible cranial geometry by single point incremental forming. Procedia Eng 132:267-273

37. Centeno G, Bagudanch I, Morales-Palma D, García-Romeu ML, Gonzalez-Perez-Somarriba B, Martinez-Donaire AJ, GonzalezPerez LM, Vallellano C (2017) Recent approaches for the manufacturing of polymeric cranial prostheses by incremental sheet forming. Procedia Eng 183:180-187

38. Bagudanch I, Garcia-Romeu ML, Ferrer I, Ciurana J (2018) Customized cranial implant manufactured by incremental sheet forming using a biocompatible polymer. Rapid Prototyp J 24(1): $120-129$

39. Bagudanch I, Centeno G, Vallellano C, Garcia-Romeu ML (2019) Towards the manufacturing of near net shape medical prostheses in polymeric sheet by incremental sheet forming, Near Net Shape Manufacturing Processes. Springer, Cham, pp 1-33

40. Lu B, Ou H, Shi SQ, Long H, Chen J (2016) Titanium based cranial reconstruction using incremental sheet forming. Int J Mater Form 9(3):361-370

41. Lu B, Xu DK, Liu RZ, Ou HA, Long H, Chen J (2015) Cranial reconstruction using double side incremental forming, Key Engineering Materials, Trans Tech Publ, pp 535-542

42. Ambrogio G, Palumbo G, Sgambitterra E, Guglielmi P, Piccininni A, De Napoli L, Villa T, Fragomeni G (2018) Experimental investigation of the mechanical performances of titanium cranial prostheses manufactured by super plastic forming and single-point incremental forming. Int J Adv Manuf Technol 98(5-8):1489-1503

43. Castelan J, Fritzen D, Daleffe A, Schaeffer L (2015) Design of custom-made cranial implant using 3D technologies and incremental sheet forming process. Inegi-Feup, Porto

44. Mohammadi A, Vanhove H, Attisano M, Ambrogio G, Duflou JR (2015) Single point incremental forming of shape memory polymer foam, MATEC Web of Conferences, EDP Sciences, p 04007

45. Hernández-Ávila M, Lozano-Sánchez L, Perales-Martínez I, ElíasZúñiga A, Bagudanch I, García-Romeu M, Elizalde L, Barrera E (2019) Single point incremental forming of bilayer sheets made of two different thermoplastics. J Appl Polym Sci 136(8):47093

46. Jackson K, Allwood J, Landert M (2008) Incremental forming of sandwich panels. J Mater Process Technol 204(1-3):290-303

47. Clavijo-Chaparro SL, Iturbe-Ek J, Lozano-Sanchez LM, Sustaita AO, Elias-Zuniga A (2018) Plasticized and reinforced poly(methyl methacrylate) obtained by a dissolution-dispersion process for single point incremental forming: enhanced formability towards the fabrication of cranial implants. Polym Test 68:39-45

48. Conte R, Ambrogio G, Pulice D, Gagliardi F, Filice L (2017) Incremental sheet forming of a composite made of thermoplastic matrix and glass-fiber reinforcement. Procedia Eng 207:819-824

49. Lozano-Sanchez LM, Sustaita AO, Soto M, Biradar S, Ge L, Segura-Cardenas E, Diabb J, Elizalde LE, Barrera EV, EliasZuniga A (2017) Mechanical and structural studies on single point incremental forming of polypropylene-MWCNTs composite sheets. J Mater Process Technol 242:218-227

50. Okada M, Kato T, Otsu M, Tanaka H, Miura T (2018) Development of optical-heating-assisted incremental forming method for carbon fiber reinforced thermoplastic sheet-Forming characteristics in simple spot-forming and two-dimensional sheetfed forming. J Mater Process Technol 256:145-153
51. Fiorotto M, Sorgente M, Lucchetta G (2010) Preliminary studies on single point incremental forming for composite materials. Int $\mathrm{J}$ Mater Form 3(1):951-954

52. Borić A, Kalendová A, Urbanek M, Pepelnjak T (2019) Characterisation of polyamide (PA) 12 nanocomposites with montmorillonite (MMT) Filler clay used for the incremental forming of sheets. Polymers 11(8):1248

53. Amar A-O, Kunke A, Kräusel V (2019) Hot single-point incremental forming of glass-fiber-reinforced polymer (PA6GF47) supported by hot air. J Manuf Process 43:17-25

54. Pickering C, Byrne J (2014) The benefits of publishing systematic quantitative literature reviews for $\mathrm{PhD}$ candidates and other earlycareer researchers. High Educ Res Dev 33(3):534-548

55. Pickering C, Grignon J, Steven R, Guitart D, Byrne J (2015) Publishing not perishing: how research students transition from novice to knowledgeable using systematic quantitative literature reviews. Stud High Educ 40(10):1756-1769

56. Silva MB, Martinho TM, Martins PAF (2013) Incremental forming of hole-flanges in polymer sheets. Mater Manuf Process 28(3):330 335

57. Ambrogio G, Gagliardi F, Conte R, Russo P (2019) Feasibility analysis of hot incremental sheet forming process on thermoplastics. Int J Adv Manuf Technol 102(1-4):937-947

58. Conte R, Gagliardi F, Ambrogio G, Filice F, Russo P (2017) Performance analysis of the incremental sheet forming on PMMA using a combined chemical and mechanical approach. In: Brabazon D, Naher S, Ahad IU (eds) Proceedings of the 20th International Esaform Conference on Material Forming. Melville, Amer Inst Physics

59. Sridhar R, Rajenthirakumar D (2016) Polymer sheet hot incremental forming - an innovative polymer forming approach. Polym Polym Compos 24(7):447-453

60. Marques T, Silva M, Martins P (2012) On the potential of single point incremental forming of sheet polymer parts. Int J Adv Manuf Technol 60(1-4):75-86

61. Hussain G, Mahna A, Iqbal A (2016) Response surface analysis of cold formability of polymers in incremental sheet forming: effect of parameters and associated thermal softening. Int J Precis Eng Manuf 17(5):613-621

62. Bagudanch I, Vives-Mestres M, Sabater M, Garcia-Romeu ML (2017) Polymer incremental sheet forming process: temperature analysis using response surface methodology. Mater Manuf Process 32(1):44-53

63. Formisano A, Durante M, Langella A, Minutolo FMC (2019) Localized heat assisted incremental forming of polycarbonate sheets by tool rotation, AIP Conference Proceedings, AIP Publishing, p 110002

64. Kulkarni S, Sreedhara VSM, Mocko G (2016) Asme, Heat assisted single point incremental forming of polymer sheets. Amer Soc Mechanical Engineers, New York

65. Jeswiet J, Hagan E, Szekeres A (2002) Forming parameters for incremental forming of aluminium alloy sheet metal. Proc Inst Mech Eng B J Eng Manuf 216(10):1367-1371

66. Edwards WL, Grimm TJ, Ragai I, Roth JT (2017) Optimum process parameters for springback reduction of single point incrementally formed polycarbonate. Procedia Manuf 10:329-338

67. Davarpanah MA, Mirkouei A, Yu XY, Malhotra R, Pilla S (2015) Effects of incremental depth and tool rotation on failure modes and microstructural properties in Single Point Incremental Forming of polymers. J Mater Process Technol 222:287-300

68. Bagudanch I, Garcia-Romeu ML, Sabater M (2016) Incremental forming of polymers: process parameters selection from the perspective of electric energy consumption and cost. J Clean Prod 112:1013-1024 
69. Durante M, Formisano A, Boccarusso L, Astarita A, Langella A (2019) Single point incremental forming of cold-rolled polycarbonate sheets, AIP Conference Proceedings, AIP Publishing, p 060007

70. Durante M, Formisano A, Lambiase F (2018) Incremental forming of polycarbonate sheets. J Mater Process Technol 253:57-63

71. Lozano-Sánchez LM, Bagudanch I, Sustaita AO, Iturbe-Ek J, Elizalde LE, Garcia-Romeu ML, Elías-Zúñiga A (2018) Singlepoint incremental forming of two biocompatible polymers: an insight into their thermal and structural properties. Polymers 10(4): 391

72. Sabater M, Garcia-Romeu ML, Vives-Mestres M, Ferrer I, Bagudanch I (2018) Process parameter effects on biocompatible thermoplastic sheets produced by incremental forming. Materials 11(8): 15

73. Medina-Sanchez G, Garcia-Collado A, Carou D, Dorado-Vicente R (2018) Force prediction for incremental forming of polymer sheets. Materials 11(9):1597

74. Silva MB, Skjoedt M, Bay N, Martins PAF (2009) Revisiting single-point incremental forming and formability/failure diagrams by means of finite elements and experimentation. J Strain Anal Eng Des 44(4):221-234

75. Silva MB, Skjoedt M, Atkins AG, Bay N, Martins PAF (2008) Single-point incremental forming and formability-failure diagrams. J Strain Anal Eng Des 43(1):15-35

76. Bagudanch I, Elias-Zuniga A, Garcia-Romeu ML (2013) Evaluating material constitutive equations for the simulation of incremental sheet forming applied to form thermoplastic materials. In: DeSousa RA, Valente R (eds) Current State-of-the-Art on Material Forming: Numerical and Experimental Approaches at Different Length-Scales, Pts 1-3. Trans Tech Publications Ltd, Stafa-Zurich, pp 1312-1319

77. Bagudanch I, Martínez-Romero O, Elías-Zúñiga A, Garcia-Romeu ML (2014) Identifying polymeric constitutive equations for incremental sheet forming modelling. Procedia Eng 81:2292-2297

78. Sy LV, Nam NT (2012) A numerical simulation of incremental forming process for polymer sheets. Int J Model Simul 32(4): 265-272

79. Yonan SA, Haupt P, Kwiatkowski L, Franzen V, Brosius A, Tekkaya A (2011) A viscoplastic material model based on overstress for the simulation of incremental sheet forming of thermoplastics, AIP conference proceedings, AIP, pp 803-808

80. Zha GC, Zhou X, Lu CK, Zhao W, Sun S, Yan AX, Li ZK (2017) Experimental study on the limit test method of polypropylene sheet incremental forming. Int J Adv Manuf Technol 93(5-8):2369-2374

81. Davarpanah MA, Bansal S, Malhotra R (2017) Influence of single point incremental forming on mechanical properties and chain orientation in thermoplastic polymers. J Manuf Sci Eng 139(2):9

82. Davarpanah MA, Bansal S, Malhotra R (2016) Mechanical properties and chain orientation in single point incremental forming of semi-crystalline polyamide, ASME 2016 11th International Manufacturing Science and Engineering Conference, American Society of Mechanical Engineers Digital Collection

83. Durante M, Formisano A, Lambiase F (2019) Formability of polycarbonate sheets in single-point incremental forming. Int $\mathrm{J}$ Adv Manuf Technol 102(5-8):2049-2062
84. Yang Z, Chen F (2020) Mechanism of twist in incremental sheet forming of thermoplastic polymer. Mater Des 195:108997

85. Silva MB, Nielsen PS, Bay N, Martins PAF (2011) Failure mechanisms in single-point incremental forming of metals. Int $\mathrm{J}$ Adv Manuf Technol 56(9-12):893-903

86. Ai S, Lu B, Chen J, Long H, Ou H (2017) Evaluation of deformation stability and fracture mechanism in incremental sheet forming. Int J Mech Sci 124:174-184

87. Cristino VA, Silva MB, Wong PK, Tam LM, Martins PA (2015) Hole-flanging of metals and polymers produced by single point incremental forming. Int J Mater Prod Technol 50(1):37-48

88. Bagudanch I, Centeno G, Vallellano C, Garcia-Romeu ML (2017) Revisiting formability and failure of polymeric sheets deformed by Single Point Incremental Forming. Polym Degrad Stab 144:366377

89. Allwood J, Shouler D, Tekkaya AE (2007) The increased forming limits of incremental sheet forming processes, Key Engineering Materials. Trans Tech Publ, Stafa-Zurich, pp 621-628

90. Zhang XB, Wang J, Zhang SQ (2017) Study on process parameters on single point incremental forming of PVC, Materials Science Forum, Trans Tech Publ, pp 74-80

91. Formisano A, Boccarusso L, Carrino L, Lambiase F, Minutolo FMC (2018) Single point incremental forming: formability of PC sheets. In: Fratini L, DiLorenzo R, Buffa G, Ingarao G (eds) Proceedings of 21 st International Esaform Conference on Material Forming. Melville, Amer Inst Physics

92. Centeno G, Bagudanch I, Martinez-Donaire AJ, Garcia-Romeu ML, Vallellano C (2014) Critical analysis of necking and fracture limit strains and forming forces in single-point incremental forming. Mater Des 63:20-29

93. Shaw MT, MacKnight WJ (2018) Introduction to polymer viscoelasticity. Wiley, Hoboken

94. Xu DK, Wu WC, Malhotra R, Chen J, Lu B, Cao J (2013) Mechanism investigation for the influence of tool rotation and laser surface texturing (LST) on formability in single point incremental forming. Int J Mach Tools Manuf 73:37-46

95. Buffa G, Campanella D, Fratini L (2013) On the improvement of material formability in SPIF operation through tool stirring action. Int J Adv Manuf Technol 66(9-12):1343-1351

96. Maßß F, Gies S, Tekkaya A (2017) Deformation characteristics of thermoplastics in single point incremental forming, AIP Conference Proceedings, AIP Publishing, p 050005

97. Al-Ghamdi KA (2018) Spring back analysis in incremental forming of polypropylene sheet: an experimental study. J Mech Sci Technol 32(10):4859-4869

98. Branker K (2011) A study of energy, carbon dioxide emissions and economics in machining: milling and single point incremental forming. Master's Thesis, Queen's University, Kingston, Ontario, Canada

Publisher's note Springer Nature remains neutral with regard to jurisdictional claims in published maps and institutional affiliations. 